\title{
Finite element modeling and validation of springback and stress relaxation in the thermo-mechanical forming of thin Ti-6Al-4V sheets
}

\author{
Eva-Lis Odenberger ${ }^{1,2} \cdot$ Robert Pederson $^{3} \cdot$ Mats Oldenburg $^{1}$
}

Received: 10 January 2019 / Accepted: 30 May 2019/Published online: 5 July 2019

(C) The Author(s) 2019

\begin{abstract}
In this work, a hot forming procedure is developed using computer-aided engineering (CAE) to produce thin Ti-6Al-4V sheet components in an effective way. Traditional forming methods involve time- and cost-consuming furnace heating and subsequent hot sizing steps. A material model for finite element $(\mathrm{FE})$ analyses of sheet metal forming and springback at elevated temperatures in Ti-6Al-4V is calibrated and evaluated. The anisotropic yield criterion proposed by Barlat et al. 2003 is applied, and the timeand temperature-dependent stress relaxation behavior for elastic and inelastic straining are modeled using a Zener-Wert-Avrami formulation. Thermo-mechanical uniaxial tensile tests, a biaxial test, and uniaxial stress relaxation tests are performed and used as experimental reference to identify material model parameters at temperatures up to $700{ }^{\circ} \mathrm{C}$. The hot forming tool setup is manufactured and used to produce double-curved aero engine components at $700{ }^{\circ} \mathrm{C}$ with different cycle times for validation purposes. Correlations between the predicted and measured responses such as springback and shape deviation show promising agreement, also when the forming and subsequent holding time was as low as $150 \mathrm{~s}$. The short cycle time resulted in elimination of a detectable alpha case layer. Also, the tool surface coating extends the tool life in combination with a suitable lubricant.
\end{abstract}

Keywords Hot forming $\cdot$ Stress relaxation $\cdot$ Springback $\cdot$ Ti-6Al-4V $\cdot$ Plastic anisotropy $\cdot$ FE analysis

\section{Introduction}

Titanium alloys are frequently used in aerospace applications due to their high strength to weight ratio and creep resistance. In load-carrying aero engine structures, titanium alloys are often used in the compressor section of an engine in which running temperatures are moderate, up to approximately 450 ${ }^{\circ} \mathrm{C}$ (c.f. Fig. 1). Traditional large single-piece castings require subsequent machining and can be extremely expensive. To reduce cost, increase design flexibility, and enable lighter weight designs, manufacturing techniques such as fabrication have become a successful path forward for the industry. The concept of fabrication involves joining thin metal sheets with

Eva-Lis Odenberger

eva-lis.odenberger@ri.se

1 Division of Mechanics of Solid Materials, Luleå University of Technology, SE-971 87 Luleå, Sweden

2 Division Materials and Production, RISE IVF AB, RISE Research Institutes of Sweden, Vällaregatan 30, SE-293 38 Olofström, Sweden

3 Division of Subtractive and Additive Manufacturing, University West, SE-461 32 Trollhättan, Sweden small forgings and castings by welding into complete engine structures. Such structures must be alpha case free to maintain component integrity [1-3].

Titanium alloys, such as Ti-6Al-4V are of interest to the aero engine industry. The alloy is challenging to form. At room temperature (RT) and medium elevated temperatures, the common microstructure of the sheet material consists of equiaxed $\alpha$ grains ( $h c p$ crystal structure), with a minor volume content of $\beta$-phase in the matrix ( $b c c$ crystal structure). In thin metal sheets, the mechanical properties are normally anisotropic with an asymmetry in yielding between tension and compression, and the alloy possesses limited ductility at room temperature. At elevated temperatures, the ductility increases, and the anisotropic uniaxial hardening is typically followed by a stress peak and a characteristic flow softening due to stress relaxation that is mainly caused by diffusion or recrystallization [4]. Thin sheet metal parts are often formed at elevated temperatures using multistage forming, sometimes with intermediate annealing and applying subsequent hot sizing to reduce excessive and scattering springback [5]. Complex geometries often require superplastic forming procedures. These procedures are time and cost consuming [6], yielding a need for developing new effective forming processes. 


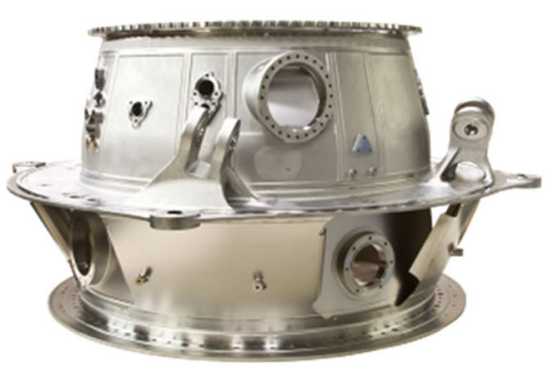

Fig. 1 The left picture shows a TRENT XWB-ICC (intermediate compressor casing). This fabricated ICC contains two different titanium alloys and is made from several different material forms (sheet, cast,

Although numerous studies have been performed to understand and model the mechanical behavior of Ti$6 \mathrm{Al}-4 \mathrm{~V}$ at different temperatures and strain rates, e.g., [7-13], and several studies related to hot forming of titanium alloys exists [14-24], further knowledge and understanding of the material behavior under hot forming conditions is essential to the exploration and success of industrial implementation of hot forming technologies in the future. In the design of new manufacturing techniques and competitive forming procedures for fabricated titanium sub-structures, a crucial task is obtaining reliable numerical predictions using the finite element method (FEM).

Numerous anisotropic yield formulations which can account for plastic anisotropy have been formulated during the past few decades and applied in FE analyses for sheet metal forming, e.g., the symmetric Hill's yield criterion [25] and Barlat and Lian's tri-component criterion [26]. These criteria contain four anisotropy coefficients for the plane stress condition and Barlat and Lian's criterion include an additional material parameter $m$ that is suggested to be equal to 6 for materials with a $b c c$ crystal structure and 8 for materials with an $f c c$ crystal structure. The $m$ parameter determines the shape edginess of the yield surface. These yield criteria are however not able to capture the observed anisotropy in both yield stress and Lankford coefficients due to the limited number of anisotropy coefficients $[22,27$, 28]. However, the anisotropic yield criteria such as Hosford and Barlat et al. [29-31] accounts for the plastic anisotropy in stress and strain using an increased number of model parameters. One applicable yield criterion for metals that possess asymmetry in yielding between tension and compression is the physically based macroscopic formulation by Cazacu et al. [32]. Such a model may be important to apply when forming procedures that subject $h c p$ crystal structured materials to both tension and compressive straining are studied. The yield criteria proposed by Barlat and Cazacu have successfully been applied to the FE analyses of thermo-mechanical forming of aluminum [33-36], Ti-6Al-4V [20-23], and magnesium [37] with modified anisotropy and symmetry parameters proposed by Ghaffari et al. [38].

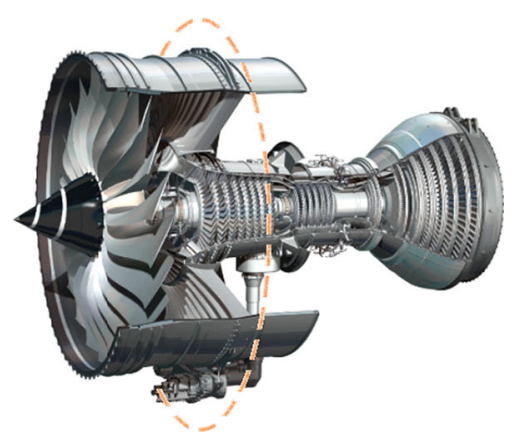

wrought, and additive manufactured material). Courtesy of GKN. The right image shows the TRENT XWB engine that power the Airbus A350 XWB. The location of the ICC is indicated

This work presents results from numerical and experimental studies of a forming procedures at elevated temperatures applying subsequent holding times in the high-tempered tool for validation purposes. The forming procedure is developed using CAE including FE analyses, aiming to minimize both springback and cycle times to obtain a time- and cost-effective forming procedure for a thin double-curved Ti-6Al-4V sheet geometry. The anisotropy and stress relaxation behavior in the elastic and plastic regimes are considered to obtain highly accurate FE predictions. The mechanical properties of the specific batch of Ti-6Al-4V are determined from uniaxial tensile tests and stress relaxation tests at elevated temperatures together with a biaxial test performed at room (ambient) temperature. The experimental reference data are used for model parameter identification for a Zener-Wert-Avrami stress relaxation function $[23,39]$ and for calibration of the anisotropic yield criterion proposed by Barlat et al. [30, 31]. The symmetric anisotropic yield criterion is chosen to evaluate its applicability for this specific hot forming case due to the requirement of a reduced number of material tests needed to calibrate the yield surface. The Barlat et al. yield criterion is applied to the hot forming FE analyses. Afterwards, the obtained stress state is transformed according to the elastic and plastic stress relaxation behavior of the alloy using a user-defined post-processing script. The novelty in this work lies in combining the anisotropic material model and FEM hot forming predictions with the Zener-Wert-Avrami stress relaxation function to include the time- and temperature-dependent relaxation effect to the springback and cooling FE analyses. The influence of stress relaxation on the predicted shape deviation was found to be significant; it is evaluated and compared with experimental observations.

\section{Material}

Specimens for the material testing and validation hot forming tests were extracted from a mill annealed thin metal sheet of Ti-6Al-4V according to AMS4911J, specified alpha case free 
by the supplier. The sheet thickness is $1.27 \mathrm{~mm}$, purchased from RTI International Metals Inc. The measured chemical composition of the specific batch of Ti-6Al-4V material is obtained from the material certificate, as presented in Table 1 . The beta transus temperature of the alloy is typically $995 \pm 15^{\circ} \mathrm{C}$ [40]. The as-received microstructure is shown in Fig. 2 which is typical for sheet materials in the mill-annealed condition and consists of equiaxed alpha grains with some retained beta phase in between.

\section{Material characterization}

A set of material tests over a temperature range of 20 to $700{ }^{\circ} \mathrm{C}$ are performed to determine the temperature-dependent elastic and inelastic anisotropic properties. In this work, uniaxial tensile tests in different in-plane directions referenced to the rolling direction, a test to produce a balanced biaxial stress state, and stress relaxation tests are used to generate the necessary experimental reference data for the material model calibrations described in Section 4. The material test procedures are described in the following subsections.

\subsection{Elastic properties}

The impulse excitation technique based on the analysis of the vibration of a test sample after being excited using a physical impulse is employed. The Resultant Frequency and Damping Analyzer (RFDA) system 23, version 6.3.0 by IMCE [41], is used to determine the Young's modulus through the relationship between the mechanical resonance frequency and the elastic properties of the specimen [41, 42]. After furnace heating to the desired test temperature, the specimen is subjected to a small mechanical impulse; the vibration is detected and analyzed. The temperature and in-plane direction dependence of the Young's modulus $\left(E_{\alpha}\right)$ referenced to the rolling direction are determined using specimens extracted along the rolling direction (00), transverse (90), and diagonal (45) direction (c.f. Fig. 3). The dimensions of the specimens used for these tests are $70 \times 20 \times 1.27 \mathrm{~mm}$.

\subsection{Inelastic properties}

The inelastic behavior of the material is characterized using uniaxial tensile tests, stress relaxation tests at room or elevated temperatures, and a viscous bulge test at room temperature.

Table 1 Chemical composition from the material certificate, of the specific batch of Ti-6Al-4V [wt\%]

\begin{tabular}{lllllllll}
\hline & $\mathrm{Al}$ & $\mathrm{O}$ & $\mathrm{N}$ & $\mathrm{Fe}$ & $\mathrm{C}$ & $\mathrm{V}$ & $\mathrm{Y}$ & $\mathrm{Ti}$ \\
\hline Alloy & 6.10 & .16 & .006 & .15 & .016 & 3.80 & $<50 \mathrm{PPM}$ & $\mathrm{Bal}$ \\
\hline
\end{tabular}

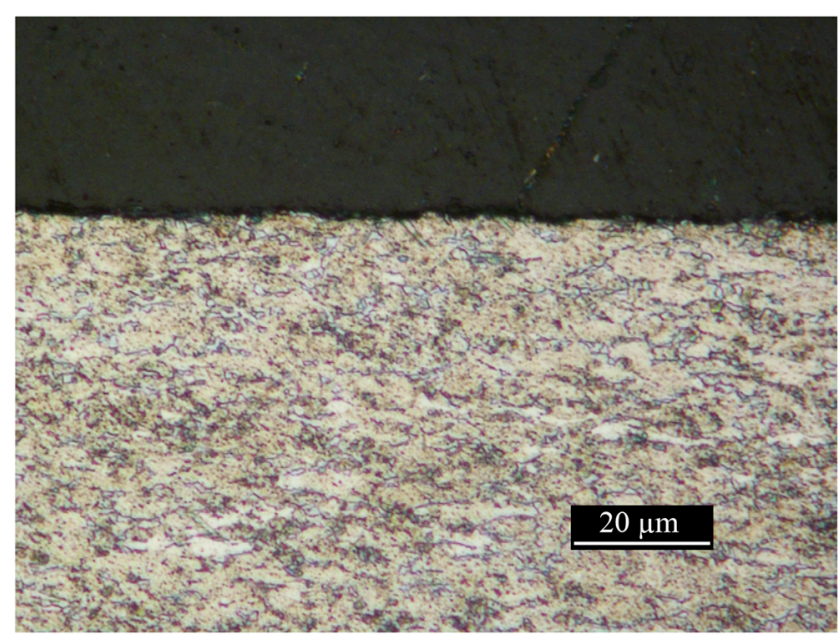

Fig. 2 The as-received micro structure of the mill annealed Ti-6Al-4V sheet, the rolling direction is horizontal in the figure

The plastic anisotropy is characterized by a difference in the yield stress and plastic flow relative to the rolling direction, as defined by the Lankford coefficient, $R_{\alpha}$, and assuming plastic incompressibility:

$R_{\alpha}=\frac{\varepsilon_{w}^{p}}{\varepsilon_{t}^{p}}=$ plastic $\quad$ incomp. $=-\frac{\varepsilon_{w}^{p}}{\varepsilon_{w}^{p}-\varepsilon_{l}^{p}}$

where $\alpha$ is the angle with respect to the rolling direction, $t$ denotes the plastic strain in the thickness direction, $w$ denotes the plastic strain in the width direction, and $l$ denotes the plastic strain in the longitudinal direction.

\subsubsection{Uniaxial tensile tests}

The uniaxial tensile tests are performed at temperatures up to $700{ }^{\circ} \mathrm{C}$ using specimens extracted in three different in-plane directions referenced to the rolling direction: along $(00)$, transverse (90), and diagonal (45). The tests are performed using an MTS tensile testing system with a load capacity of $100 \mathrm{kN}$ and a strain rate of $0.003 \mathrm{~s}^{-1}$ to a $0.2 \%$ engineering strain followed by a strain rate of $0.009 \mathrm{~s}^{-1}$. The sudden change in hardening at $600{ }^{\circ} \mathrm{C}$ and $700{ }^{\circ} \mathrm{C}$ is due to the change in strain rate (c.f. Fig $5 \mathrm{~b})$. The tests are performed until rupture. In the elevated temperature tests, inductive heating is applied using a coil designed to generate an evenly distributed temperature field (maximum deviation of $\pm 7.5^{\circ} \mathrm{C}$ at $700{ }^{\circ} \mathrm{C}$ ) in the evaluated region of the specimen (see example in Fig. 4). In contrast to tensile testing in room temperature, the temperature filed is evenly distributed throughout the test without excessive deformation heating due to the temperature and feedback control system ensuring the target temperature during the testing procedure. The evaluation region is in this case chosen such that it includes the necking area, which is typically $10 \times 12 \mathrm{~mm}$ in size. Specimen deformation is observed and calculated using 
Fig. 3 Young's modulus as a function of the temperature and in-plane direction referenced to the rolling direction. Linear trend lines; blue correspond to (00)direction, green (45)-direction, and red (90)-direction

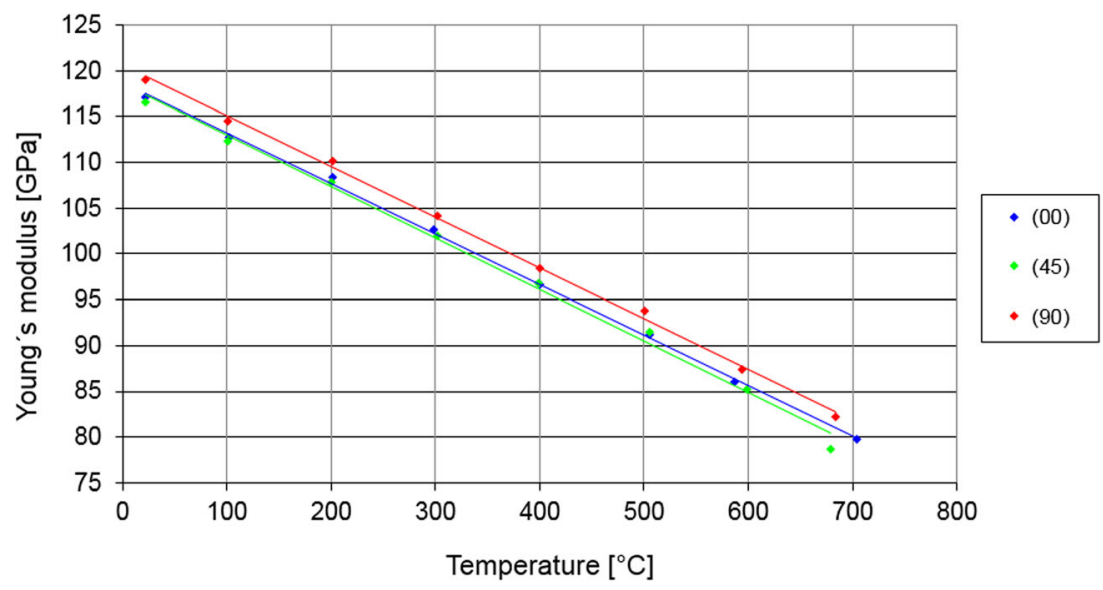

digital image correlation (DIC), an ARAMIS ${ }^{\mathrm{TM}}$ optical measuring system using a 50-Hz CCD camera to record images of the progressively elongated samples in combination with optical camera filters and blue light illumination [43]. An appropriate stochastic pattern is applied on the sandblasted specimen surfaces that are capable of resisting high temperatures. The temperature is measured and controlled using $\mathrm{Ni} / \mathrm{Cr}-\mathrm{Ni}$ thermocouples (type $\mathrm{K}$ ) attached to the center surface on the sample at half of the length. IR camera pictures are used to determine the temperature distribution or deviance in temperature of the specimens, the emissivity is calibrated against the thermo couple. During the test procedure, the force and the axial and width displacements (using video extensometers when performed at room temperature) are measured and logged to obtain the initial yield stress, Lankford parameters, and true stress-true strain curves. The tests are continuously monitored using the ARAMIS ${ }^{\mathrm{TM}}$ optical strain measuring system [44]. The evaluation is performed locally within the localized zone corresponding to the chosen temperature field( c.f. Figs. 4 and 5). The effect of the increase in strain rate to the flow stress curves upon localization is limited by considering data only up to a strain rate increase of five times the target strain rate.

\subsubsection{Viscous bulge test}

The viscous bulge test [45] is performed at room temperature to obtain a balanced biaxial stress state to determine the equibiaxial initial yield stress, $\sigma_{\mathrm{b}}$, and Lankford coefficient, $R_{\mathrm{b}}$, at an experimental reference point $\left(\sigma_{\mathrm{b}},-\varepsilon_{\mathrm{t}}\right)$. During the test, the ARAMIS $^{\text {TM }}$ strain measurement system is used to continuously measure surface strains and geometry (radius of the dome). The pressure is continuously measured using a sensor at the bottom of the silicone rubber punch to determine the biaxial stress according to Eq. 2.

$\sigma_{\mathrm{b}}=\frac{p \cdot r_{\mathrm{b}}}{2 t_{\mathrm{b}}}$
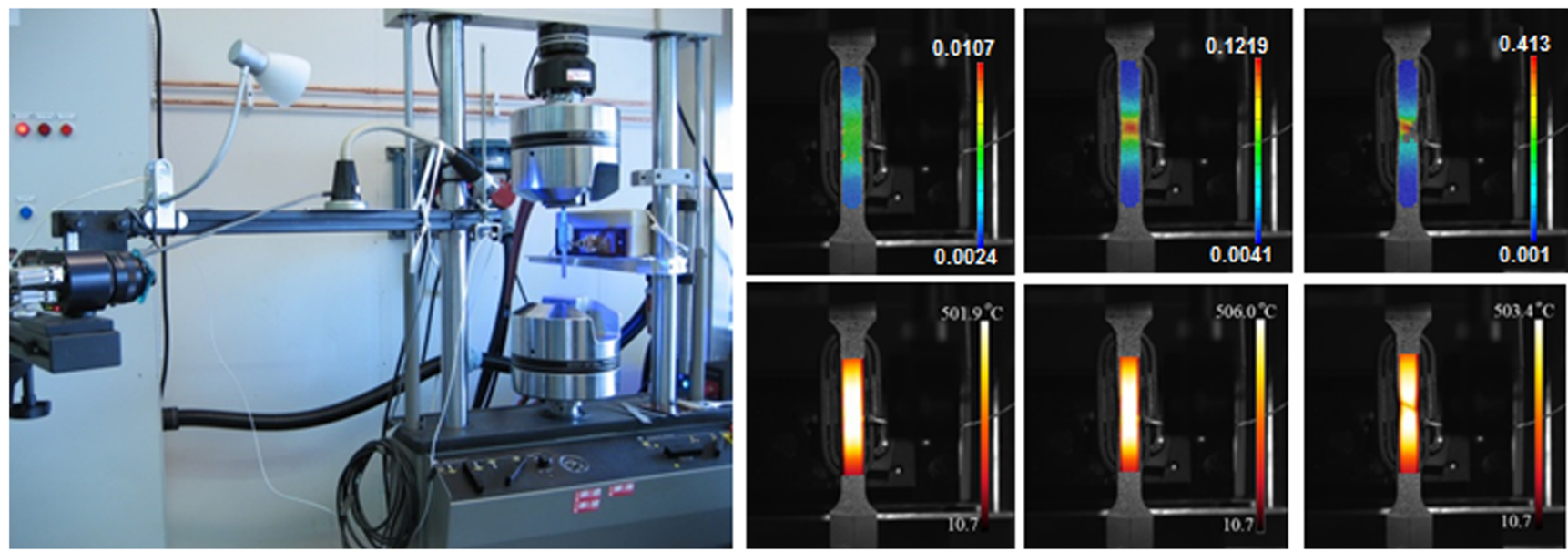

Fig. 4 Illustration of the thermo-mechanical uniaxial tensile test setup with examples of true strain and temperature fields 
Fig. 5 True stress-true strain curves at different temperatures and in-plane directions referenced to the rolling direction. a At 20 ${ }^{\circ} \mathrm{C}$. b At $400{ }^{\circ} \mathrm{C}$. c at $600{ }^{\circ} \mathrm{C}$. d At $700{ }^{\circ} \mathrm{C}$ a

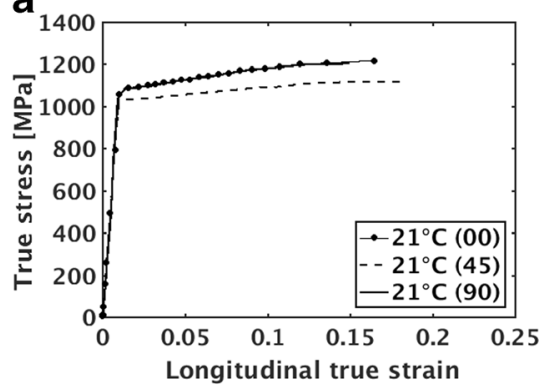

C

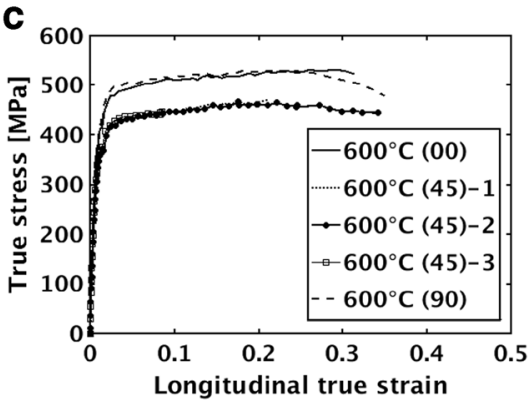

b

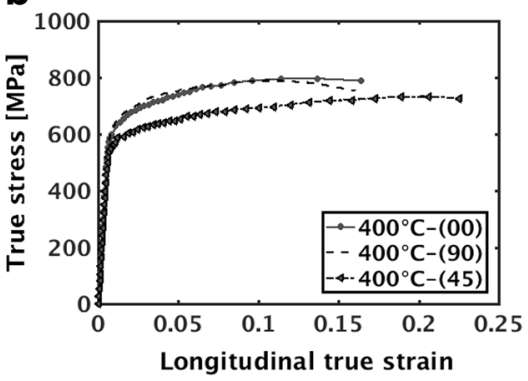

d

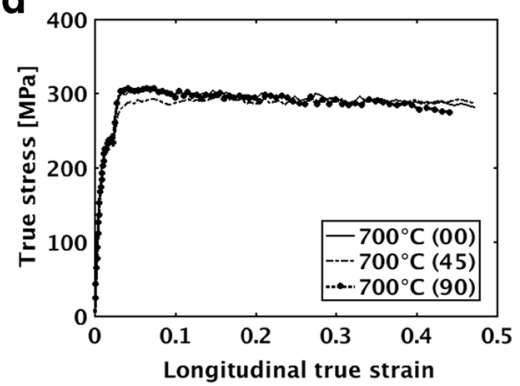

The experimental reference point is chosen from the true stress-true thickness strain curve (c.f. Fig. 6 and expression 3). High-temperature tests were not possible using the current test setup due to the silicon material of the punch. Therefore, biaxial elevated temperature reference data are scaled and assumed to follow the change in the initial yield stress with temperature, in the uniaxial tensile tests along the rolling direction (00). The biaxial reference point at $700{ }^{\circ} \mathrm{C}$ is assumed according to expression 4.

$$
\begin{aligned}
& \operatorname{REF}_{21}\left(\sigma_{\mathrm{b}},-\varepsilon_{\mathrm{t}}\right)=(1180.6,0.035) \\
& \operatorname{REF}_{700}\left(\sigma_{\mathrm{b}},-\varepsilon_{\mathrm{t}}\right)=(319.2,0.035)
\end{aligned}
$$

\subsubsection{Stress relaxation tests}

Isothermal uniaxial stress relaxation tests are performed at temperatures up to $700{ }^{\circ} \mathrm{C}$ with specimens extracted along the rolling direction (00) using an MTS 810 test system with a load capacity of $100 \mathrm{kN}$ and furnace heating to the desired test temperatures (c.f. Fig. 7). The specimens are strained to a specific strain value, after which the displacement is kept constant for $900 \mathrm{~s}$. During the test procedure the axial displacement, force, and temperature are measured and logged. The temperature is measured and controlled using $\mathrm{Ni} / \mathrm{Cr}-\mathrm{Ni}$ thermocouples (type K) attached to the sample edge at half of the length.

The measured force response during the tests at different strain values and temperatures are used to obtain true stress vs. time curves (c.f. Fig. 11).
Fig. 6 Biaxial true stress-true thickness strain curve at room temperature

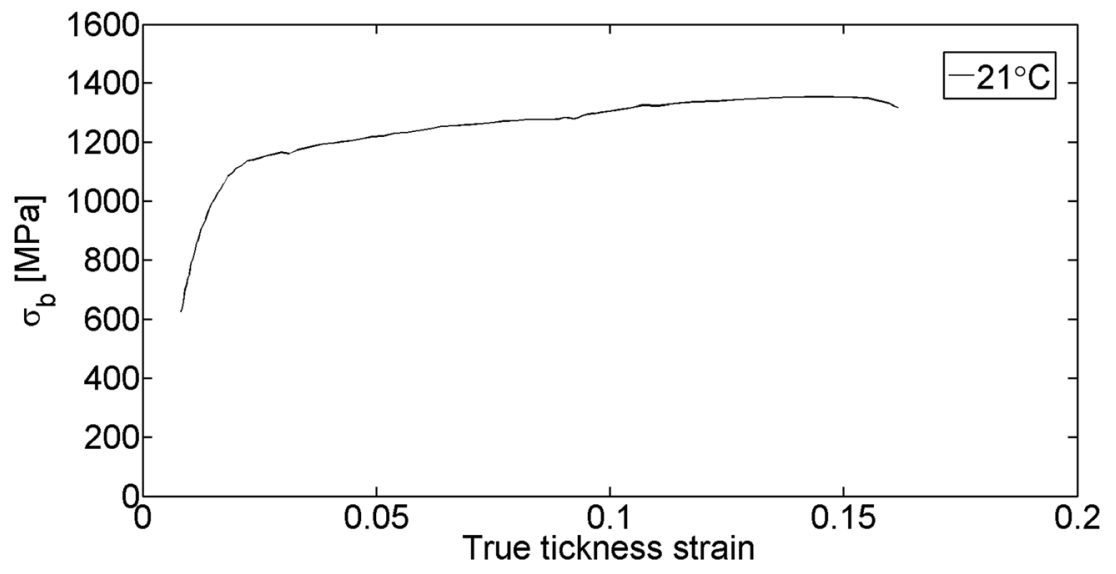


Fig. 7 Test setups for isothermal elevated temperature stress relaxation tests. Courtesy of Luleå University of Technology and GKN Aerospace Engine Systems Sweden, respectively
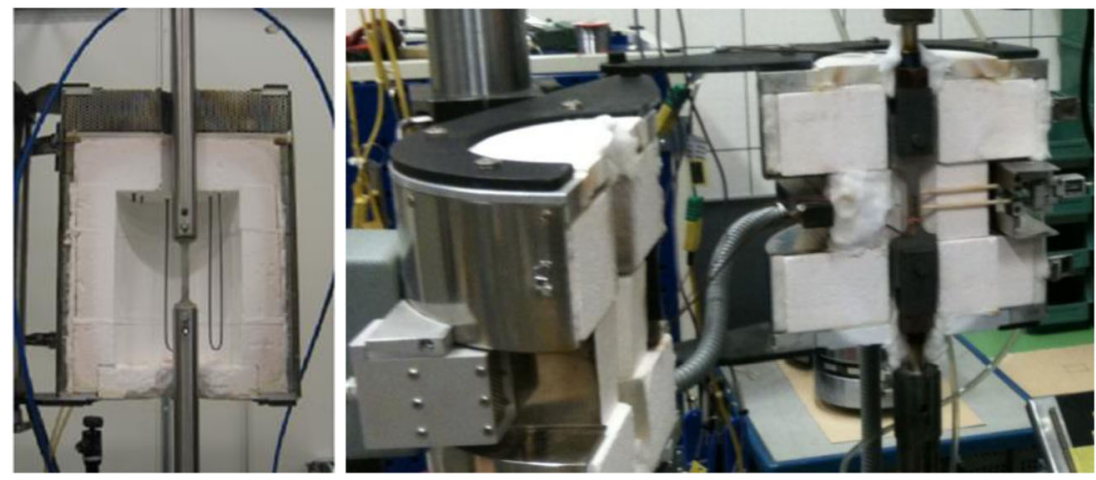

\section{Model calibration}

The material model parameters are determined from the experimental reference data to calibrate the yield criterion with respect to both yield stress and Lankford coefficients. The stress relaxation model is calibrated using the stress relaxation tests at different temperatures and strain levels.

\subsection{Yield criterion and anisotropy parameters}

In this work, the shape of the yield surfaces is determined using a material testing and identification scheme that minimizes the objective function in a least-squares sense using LSDYNA [46]. The experimental reference data at different temperatures ranging from room temperature up to $700{ }^{\circ} \mathrm{C}$ consists of data such as the initial yield stress, hardening, and Lankford coefficients determined from the uniaxial tensile tests performed in the 00,45 , and 90 directions referenced to the rolling direction. Furthermore, the balanced biaxial yield stress, $\sigma_{\mathrm{b}}$, and the biaxial $R$ value, $R_{\mathrm{b}}$, are used. These were obtained using the experimental biaxial reference point measured during biaxial tension $\left(\sigma_{11}=\sigma_{22}\right)$ in the viscous bulge test according to expressions 3 and 4 . The biaxial $R$ value is determined according to Eq. 1. The biaxial yield stress, $\sigma_{\mathrm{b}}$, is determined by applying the results from the uniaxial tensile tests and calibrating the Barlat et al. (2003) yield surface to obtain an experimental reference point response in Eqs. 3 and 4 by applying a biaxial tension to a fully integrated shell element using FE analyses. The biaxial data are transformed to $700{ }^{\circ} \mathrm{C}$ assuming the room temperature behavior, i.e., the room temperature data are scaled to the desired elevated temperature based on the percent difference between the room temperature and elevated temperature uniaxial tensile yield stress data along the rolling direction (00).

Barlat et al. [30,31] proposed an anisotropic yield criterion composed of two convex functions formulated as

$f=\Phi^{\prime}+\Phi^{\prime \prime}-2 \bar{\sigma}_{-f}^{m}=0$

where:

$\Phi^{\prime}=\left|X_{1}^{\prime}-X_{2}^{\prime}\right|^{m}$

and:

$\Phi^{\prime \prime}=\left|2 X_{2}^{\prime \prime}-X_{1}^{\prime \prime}\right|^{m}+\left|2 X_{1}^{\prime \prime}+X_{2}^{\prime \prime}\right|^{m}$

where $X_{1,2}^{\prime}$ and $X_{1,2}^{\prime \prime}$ are the principal values of the linearly transformed stress deviator matrices $\{s\}$ :

$\left\{X^{\prime}\right\}=\left[C^{\prime}\right]\{s\}$

$\left\{X^{\prime \prime}\right\}=\left[C^{\prime \prime}\right]\{s\}$

The exponent $m$ is a parameter that describes the shape edginess of the yield surface. For an $m$ value equal to 2, the yield surface reduces to the Hill yield surface when applying only four anisotropy coefficients, and to the von Mises yield
Table 2 Calibration data for Ti$6 \mathrm{Al}-4 \mathrm{~V}$ at different temperatures. The initial yield stress, $\sigma_{\alpha}$, is shown in $\mathrm{MPa}$

\begin{tabular}{lllllllll}
\hline Temp $\left({ }^{\circ} \mathrm{C}\right)$ & $\sigma_{00}$ & $\sigma_{45}$ & $\sigma_{90}$ & $\sigma_{\mathrm{b}}$ & $R_{00}$ & $R_{45}$ & $R_{90}$ & $R_{\mathrm{b}}$ \\
\hline Ambient & 1070.0 & 1025.1 & 1062.0 & 1124.9 & 0.745 & 1.499 & 0.569 & 1.049 \\
600 & 464.9 & 402.0 & 478.1 & 489.2 & 0.511 & 1.011 & 0.506 & 1.049 \\
700 & 296.1 & 274.0 & 299.0 & 311.5 & 0.500 & 0.862 & 0.568 & 1.049 \\
\hline
\end{tabular}


Table 3 Barlat et al. parameter values for Ti-6Al-4V at different temperatures

\begin{tabular}{lllllllll}
\hline Temp $\left({ }^{\circ} \mathrm{C}\right)$ & $\alpha_{1}$ & $\alpha_{2}$ & $\alpha_{3}$ & $\alpha_{4}$ & $\alpha_{5}$ & $\alpha_{6}$ & $\alpha_{7}$ & $\alpha_{8}$ \\
\hline Ambient & 1.014 & 0.8942 & 0.8424 & 0.9994 & 0.9887 & 0.8883 & 1.061 & 1.098 \\
600 & 0.9503 & 0.8843 & 0.8893 & 0.9854 & 0.9976 & 0.8480 & 1.117 & 1.427 \\
700 & 0.9036 & 0.9515 & 0.8774 & 0.9915 & 0.9993 & 0.8443 & 1.041 & 1.273 \\
\hline
\end{tabular}

surface in the isotropic case. An increasing value of $m$ corresponds to an increasing shape edginess of the yield surface. The matrices $C^{\prime}$ and $\mathrm{i}^{\prime \prime}$ can be expressed in terms of eight anisotropy coefficients $\alpha_{i}$, which all reduce to unity in the isotropic case.

In this work, the initial yield stresses $\sigma_{00}, \sigma_{45}$, and $\sigma_{90}$; the Lankford coefficients $R_{00}, R_{45}$, and $R_{90}$ determined from uniaxial tensile tests and the biaxial yield stress, $\sigma_{\mathrm{b}}$; and the biaxial Lankford coefficient, $R_{\mathrm{b}}$ are used to determine the anisotropy coefficients $\alpha_{1}-\alpha_{8}$. The yield stress data and Lankford coefficients used in the calibration are presented in Table 2, and the resulting anisotropy coefficients are presented in Table 3. The rolling direction of the Ti-6Al-4V blank is used as a reference in the calibrations and is denoted as 11 . The resulting yield surfaces at $700^{\circ} \mathrm{C}$ are shown in Fig. 8 for different amounts of shear stress. In Figs. 9 and 10, the predicted initial yield stress $\sigma_{\mathrm{Y}}$ and the $R$ values are compared to the measured values, assuming an $m$ value of 8 for the different temperatures and angle directions $(\alpha)$ referenced to the rolling direction (00).

\subsection{Stress relaxation model}

The Zener-Wert-Avrami function [39], described in Eq. 10, is used to model the stress relaxation behavior for both elastic and inelastic loading. The model parameters are determined using the stress relaxation tests as experimental references in an inverse modeling procedure. The objective function is minimized in a least-squares sense using the unconstrained subspace-searching simplex method [47], the objective function $(\varphi)$ is described in Eq. 11 and the optimized parameters for different temperatures and strain levels are presented in Table 4. Optimizations were performed using different initial guesses and a lower boundary was set for the reference stress $\sigma_{0}$ to be greater than zero. The resulting objective function value decreased by $97.4 \%$ compared to the initial objective function value due to the inverse modelling procedure.

$\sigma=\sigma_{0} \exp (-A t)^{m} ; A=B \exp \left(-\frac{\Delta H}{k T}\right)$

where $m$ is a numerical parameter that is dependent on the dominant relaxation mechanism, $t$ is the time, $B$ is a constant, $k$ is the Boltzmann constant, $T$ is the temperature, and $\Delta H$ is the activation enthalpy for the relaxation process. The experimental response and model predictions are presented in Fig. 11.

$\varphi\left(D_{i}\right)=\frac{1}{2} \sum_{j=1}^{N}\left(\sigma_{j}^{e x p}-\sigma_{j}^{E q .}\right)^{2} ; \quad i=1,2,3,4$

where $D_{i}$ is the design variables $\sigma_{0}, m, B$, and $\Delta H$.

\section{Finite element model}

The Dynaform pre-processor [48] and the explicit FE software LS-DYNA v971 [46] was used to model the forming
Fig. 8 Ti-6Al-4V yield surface at $700{ }^{\circ} \mathrm{C}$ determined using eight parameters, along with $m=8$, with the Barlat et al. criterion for equal amounts of shear stress $\sigma_{12} / \bar{\sigma}$. The experimental reference points are illustrated

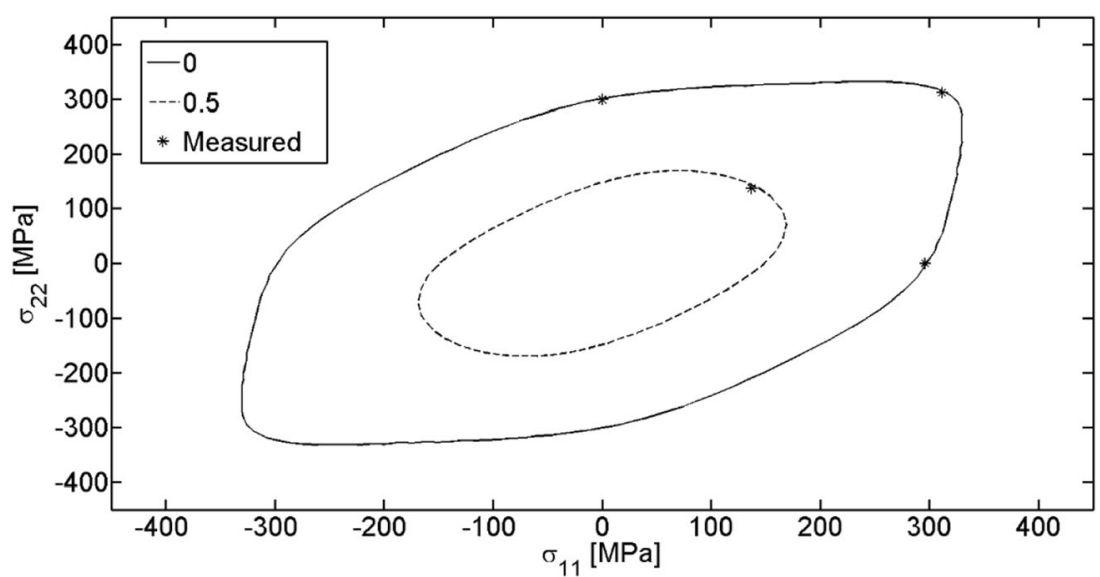


Fig. 9 Predicted and measured initial yield stress, $\sigma_{\mathrm{Y}}$, using eight parameters and $m=8$ at the indicated temperatures and inplane directions referenced to the rolling direction

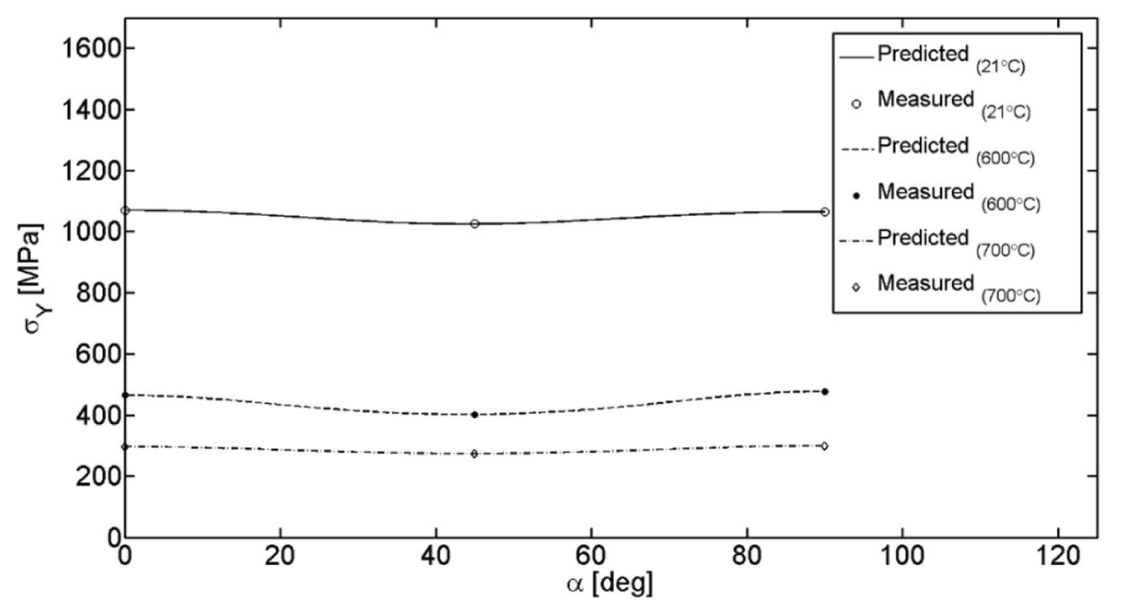

procedure and solve the equations of motion. The unit settings used is $\mathrm{mm}$, ton, sec, $\mathrm{N}$. The material model used for the FE analyses of the hot sheet metal forming of the Ti-6Al-4V is a rate independent elastic-plastic model with isotropic hardening. The anisotropic plastic behavior is described using the presented yield criterion proposed by Barlat et al. [29]. The nonlinear hardening is defined as tabulated values of yield stress and effective plastic strain. Isotropic elastic temperature dependent properties are assumed for the forming, stress relaxation, cooling, and springback analyses, approximated to the values in the rolling direction (00). The general simulation setup consists of a die, a blank, and a punch as shown in Fig. 12. A total of 13645 fully integrated shell elements with 9 integration points through the thickness are used to model the blank (c.f. Fig. 13). The tool surfaces are modelled as rigid with a prescribed velocity profile of $5 \mathrm{~mm} / \mathrm{s}$ using a speedup factor of 100 and assuming a constant, isothermal temperature of $700{ }^{\circ} \mathrm{C}$. The contact between the tool parts and blank is included and modeled as a contact interface with a friction model assumed to follow Coulomb's friction law. A friction coefficient of 0.25 was chosen based on the correlations between the predicted and measured draw-in and punch force observed during previous validation tests of thermomechanical forming in titanium [21]. The stress relaxation model is applied through a user post-processing script transforming the obtained stress state after hot forming into the "hot-sized" residual stress state assuming isotropic relaxation behavior under isothermal conditions at $700{ }^{\circ} \mathrm{C}$. The user post-processing script is a Fortran 77 code that uses the stress state from the hot forming FE analysis found in the *INITIAL_STRESS_SHELL card of the dynain file as input. A new stress state is calculated using the Zener-Wert-Avrami function with the optimized model parameters along with the holding temperature and time. The script enters the hot-sized stress state into the dynain file which is used with the implicit solver in LS-DYNA v971 for the subsequent cooling and springback analyses.

The constrained nodes in the springback analyses were altered to ensure that the obtained shape deviation is not affected by the choice of nodal constraints. The definition of shape deviation and cross sections for which the shape deviations are presented is illustrated in Fig. 14.
Fig. 10 Predicted and measured, $R_{\alpha}$, using eight parameters and $m$ $=8$ at the indicated temperatures and in-plane directions referenced to the rolling direction

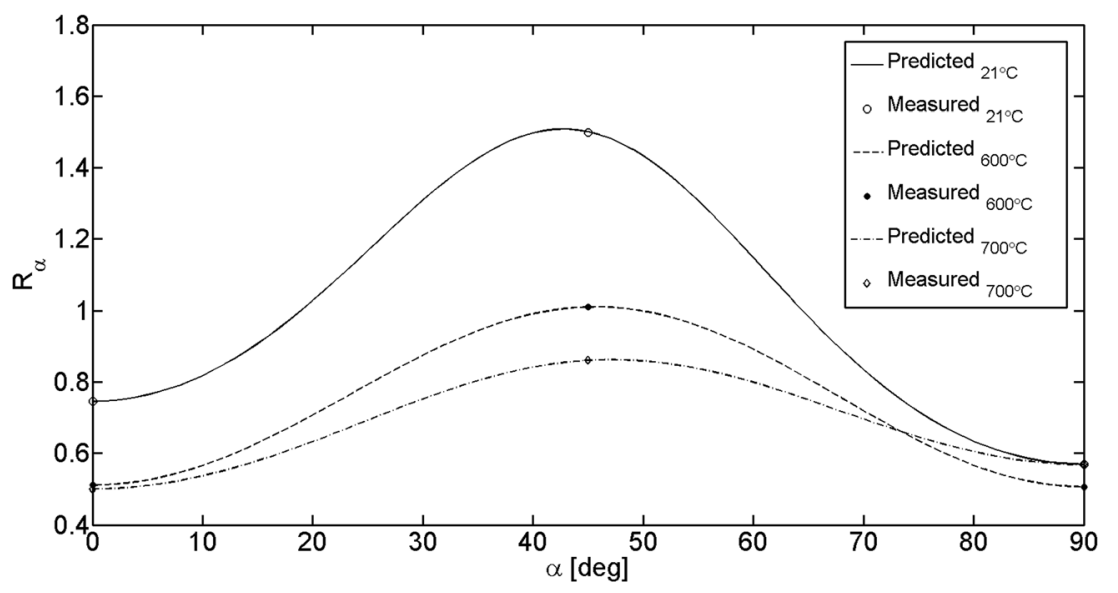


Table 4 Summary of the determined model parameters. The strain value corresponds to total $\log$ strain $\varepsilon_{\text {tot }}$

\begin{tabular}{llllll}
\hline$\varepsilon_{\text {tot }}$ & Temp $\left({ }^{\circ} \mathrm{C}\right)$ & $\sigma_{0}(\mathrm{MPa})$ & $m$ & $B$ & $\Delta H$ \\
\hline 0.0025 & 700 & 97.800 & 0.2488 & $\begin{array}{c}1.7785 \mathrm{e}+ \\
14\end{array}$ & 2.8543 \\
0.005 & 700 & 187.000 & 0.2488 & $\begin{array}{c}1.7785 \mathrm{e}+ \\
14\end{array}$ & 2.8543 \\
0.01 & 700 & 304.511 & 0.2531 & $\begin{array}{c}1.9472 \mathrm{e}+ \\
14\end{array}$ & 2.8517 \\
0.0050 & 550 & 68.194 & 0.3809 & $\begin{array}{c}1.7828 \mathrm{e}+ \\
14\end{array}$ & 2.8335 \\
0.0076 & 550 & 242.78 & 0.3809 & $\begin{array}{c}1.7828 \mathrm{e}+ \\
14\end{array}$ & 2.8335 \\
0.0402 & 550 & 564.75 & 0.3809 & $\begin{array}{c}1.7828 \mathrm{e}+ \\
14\end{array}$ & 2.8335 \\
0.0060 & 400 & 372.505 & 0.2931 & $\begin{array}{c}1.8077 \mathrm{e}+ \\
16\end{array}$ & 3.0059 \\
0.0100 & 400 & 586.435 & 0.2814 & $\begin{array}{c}9.8900 \mathrm{e}+ \\
13\end{array}$ & 2.5472 \\
0.0340 & 400 & 657.296 & 0.2814 & $9.8900 \mathrm{e}+$ & 2.5472 \\
& & & & 13 & \\
\hline
\end{tabular}

\section{Application example}

A hot forming tool was designed and manufactured to perform forming validation tests at temperatures up to $700{ }^{\circ} \mathrm{C}$ to produce the desired double-curved part geometry. The different
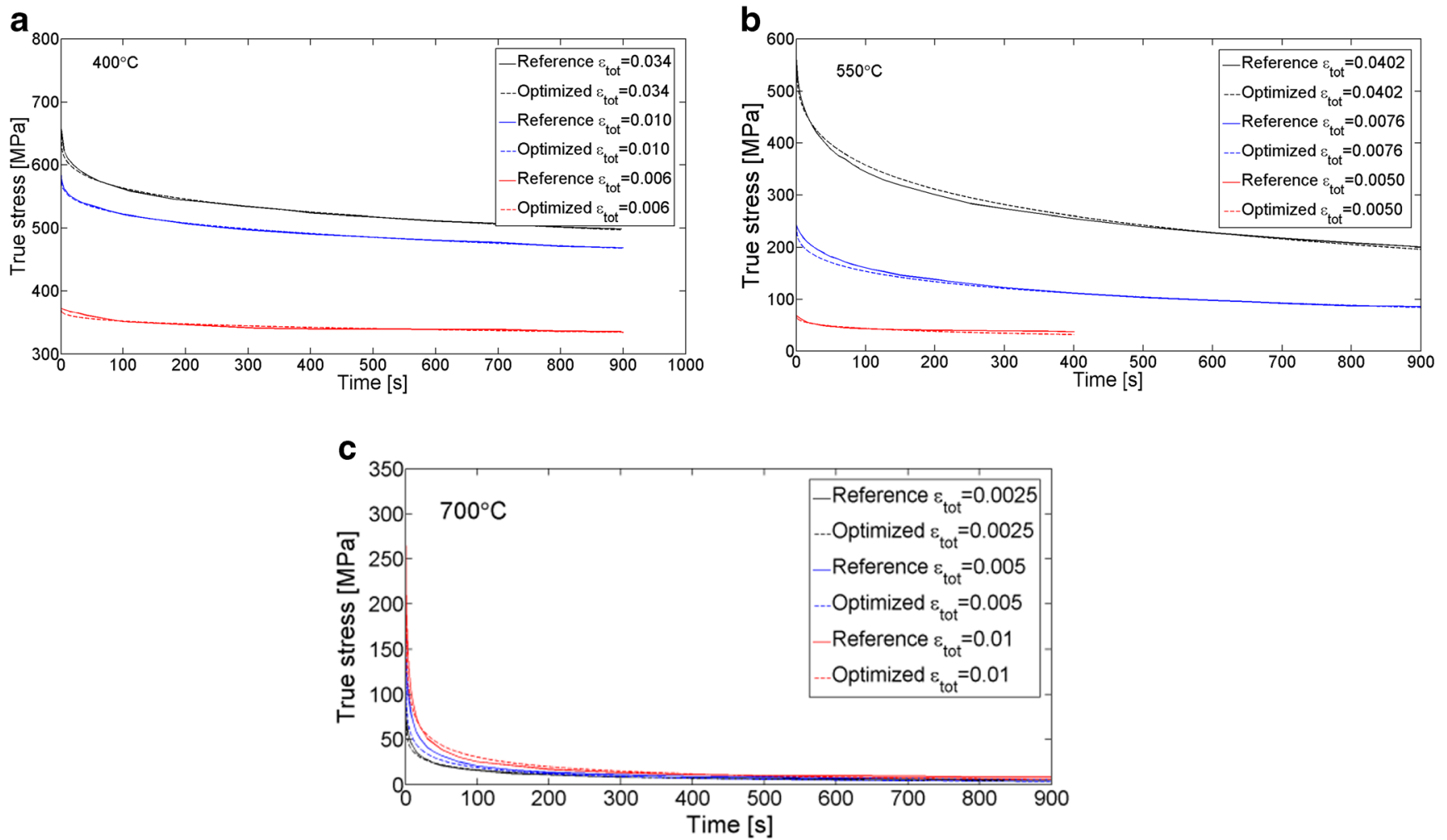

Fig. 11 Experimental and optimized stress relaxation curves at different temperatures and strain levels for the specimens extracted along the rolling direction (00) at a $400{ }^{\circ} \mathrm{C}, \mathbf{b} 550{ }^{\circ} \mathrm{C}$, and $\mathbf{c} 700{ }^{\circ} \mathrm{C}$ 


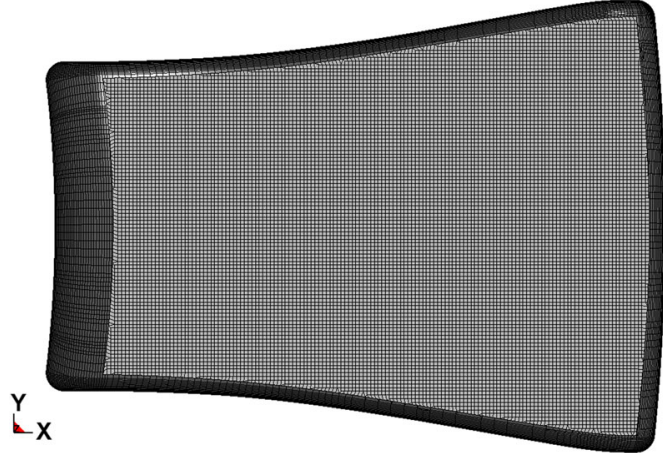

Fig. 13 FE element mesh of the blank and punch

Fig. 14 Definition of a the shape deviation and $\mathbf{b}$ section lines for which the shape deviation is presented. The distance " $\mathrm{x}$ " is determined from the wider back edge to the specific cross section in $\mathrm{mm}$

a
四 BLANK

@ PUNCH

measured at two points in each elevated temperature tool part using mineral-insulated thermocouples (type K) according to DIN 43710 and EN 60 584. One thermocouple is used for temperature feedback and regulation; the other is used for temperature logging during the forming procedures.

The blank (orange in the left-hand side and white in the upper right-hand side pictures in Fig. 15) was pre-heated for $300 \mathrm{~s}$ in a furnace to a temperature of $720^{\circ} \mathrm{C}$ before being placed into the hot forming tool. A direct hot crash forming procedure $\left(F_{1}\right)$ was compared with two other hot crash forming procedures including subsequent holding times in

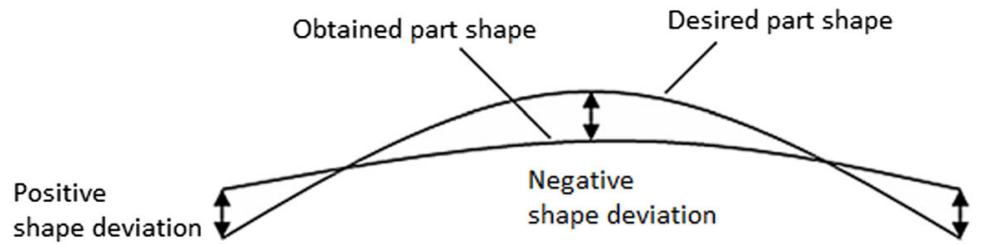

b

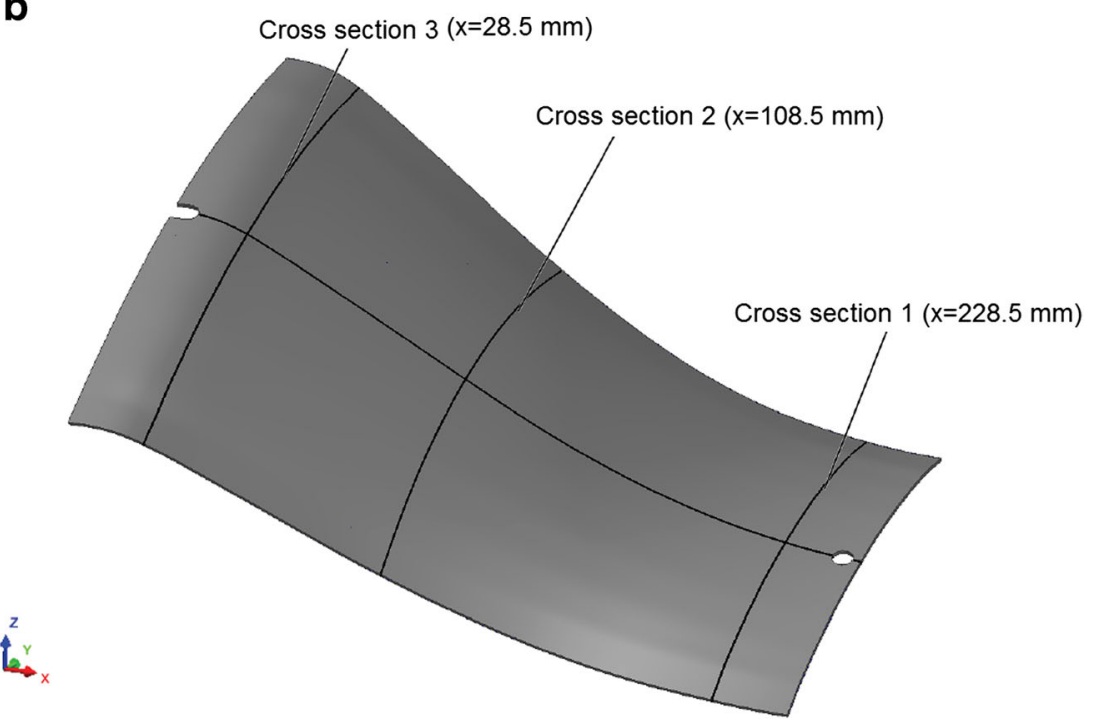

Fig. 15 CAD illustration of the tool setup for the Ti-6Al-4V hot forming tests and the produced geometry

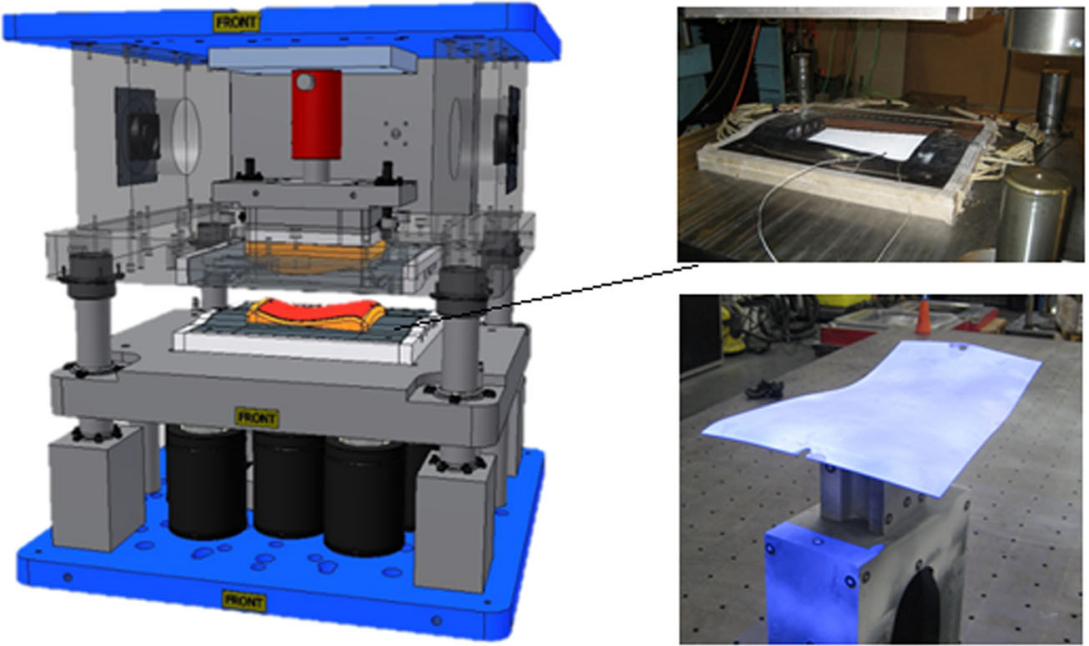



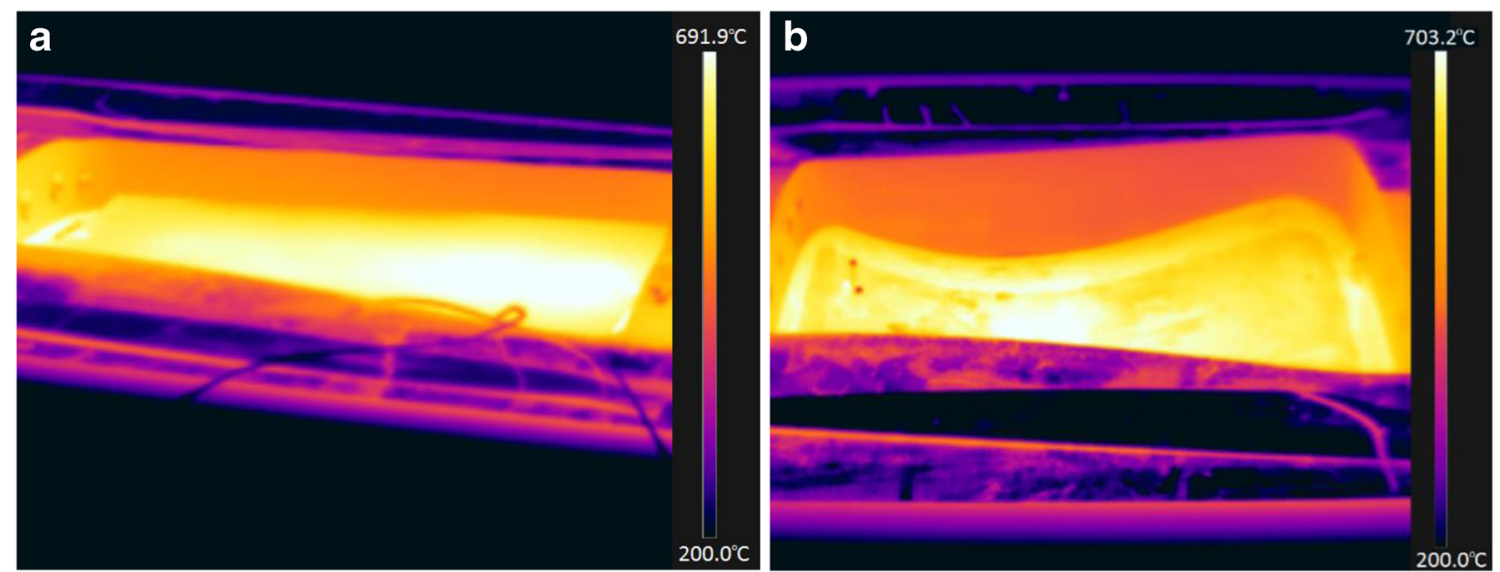

Fig. 16 IR camera images from the hot forming test $\left(F_{2}\right)$ including the punch and blank. a Immediately prior to forming. b After forming

the closed tool state $\left(F_{2}, F_{3}\right)$. The holding times were $150 \mathrm{~s}$ $\left(F_{2}\right)$ and $900 \mathrm{~s}\left(F_{3}\right)$. After forming, the component was removed and air cooled to room temperature. Boron nitride was chosen as the lubricant between the punch/die and the blank during the hot forming procedures performed at $680 \pm$ $25^{\circ} \mathrm{C}$ (c.f. Fig. 16). The emissivity $(\varepsilon=0.78)$ was adjusted to obtain equal temperatures between the IR camera images and thermocouples (type k) at two surface reference points on the punch.

\section{Results and evaluation}

The anisotropy at elevated temperatures is determined from the material characterization tests presented in Section 3. The temperature-dependent elastic properties are slightly anisotropic (see Fig. 3). The initial yield stress in the 45-direction is comparatively lower than in the two other directions $(00$, 90), whereas the Lankford coefficients is substantially higher in the 45-direction compared to the other two directions. This was observed for all the evaluated temperatures. Stress relaxation causing permanent deformation occurs for both elastic

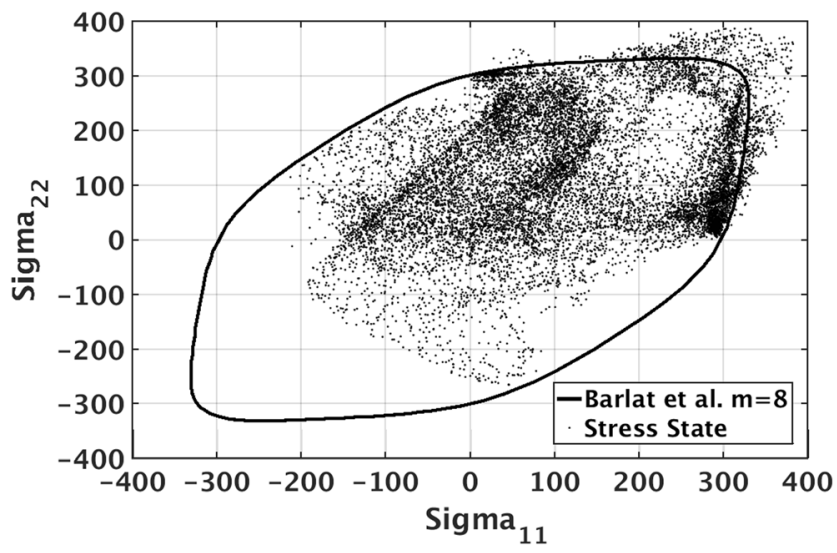

Fig. 17 The Ti-6Al-4V initial yield surface at $700{ }^{\circ} \mathrm{C}$ using the Barlat et al. criterion and predicted FEA stress state in the hot forming procedure in the closed tool stage before subsequent holding times, $\sigma_{12}=0$ and plastic loading of the Ti-6Al-4V. The rate of the force decrease, i.e., the stress decrease with time during the stress relaxation tests depends on the temperature, time, and initial loading, i.e., strain level. The influence of the temperature and time on the rate of stress relaxation is greater than the strain level, which was also concluded by Deng et al. [11]. Finding the global minima, a unique solution to an optimization problem such as in the inverse modelling procedure to identify the stress relaxation model parameters, is a difficult task. Often, several local minima exist that may be acceptable solutions. In this work, several initial guesses of the design variables were used, and a lower boundary was added for the reference stress to be greater than zero as a strategy to approach a unique solution. It was not found possible to use one single set of model parameters to describe the complete stress relaxation behavior of Ti-6Al$4 \mathrm{~V}$ at all temperatures and initial strain levels. Instead, different sets of parameters were found necessary for the three temperatures studied, in the elastic regime at $400{ }^{\circ} \mathrm{C}$ and for the highest strain level at $700{ }^{\circ} \mathrm{C}$. This indicates that some of the model parameters $m, B$, and $\Delta H$ are temperature and/or strain dependent.

The produced parts from the hot forming tests are measured for shape deviations using a laser scanning and best-fit CAD evaluation procedure with Zeiss TSCAN CS, as shown in Fig. 14 and the lower right part of Fig. 15. The crash forming procedure used in this work produce a stress state according to Fig. 17. The stress state in the final closed stage of the forming procedure at $700{ }^{\circ} \mathrm{C}$ is plotted along with the Barlat et al. initial yield surface. Most of the formed part is still in the elastic region; the material enters the plastic region in the positive $\sigma_{11} / \sigma_{22}$ quadrant which indicates that the symmetric anisotropic yield criterion is applicable to predict the responses from the hot crash forming procedure of interest to this study. The CPU time for the hot forming analyses using $16 \mathrm{SMP}$ threads was $37 \mathrm{~min}$ and $45 \mathrm{~s}$. 
Fig. 18 a Measured and $\mathbf{b}$ predicted shape deviation $(\mathrm{mm})$ of the produced geometry hot formed at approximately $700{ }^{\circ} \mathrm{C}$ without a subsequent holding time in the closed stage of the tool $\left(F_{1}\right)$. $\mathbf{c}$ Measured sections and $\mathbf{d}$ predicted sections of shape deviation $(\mathrm{mm})$ a

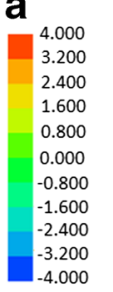

b

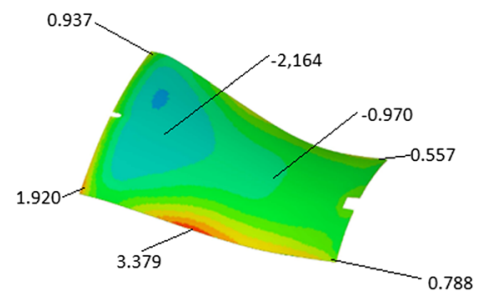

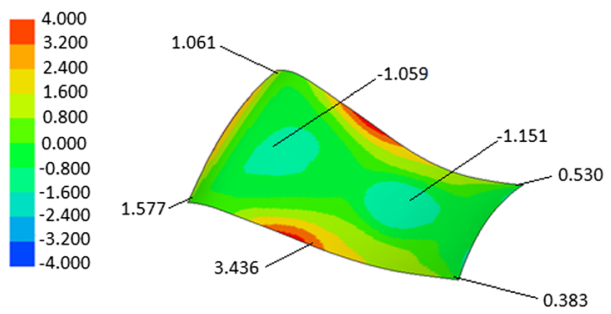

C

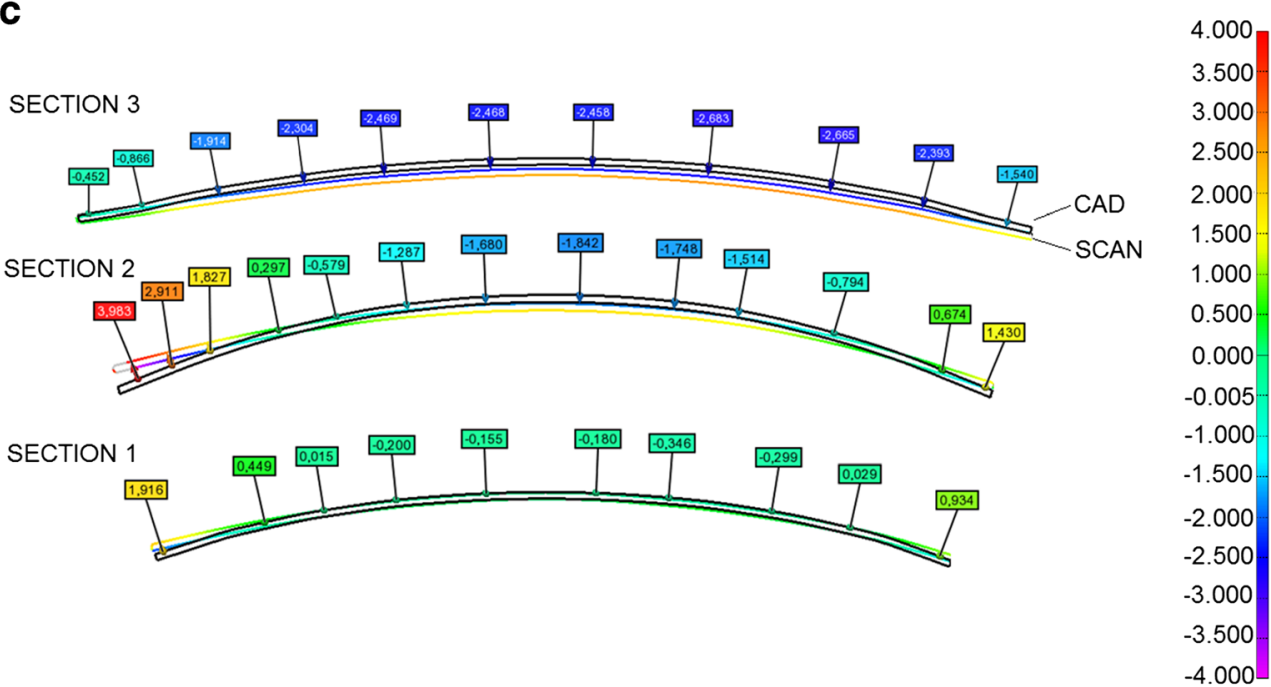

d

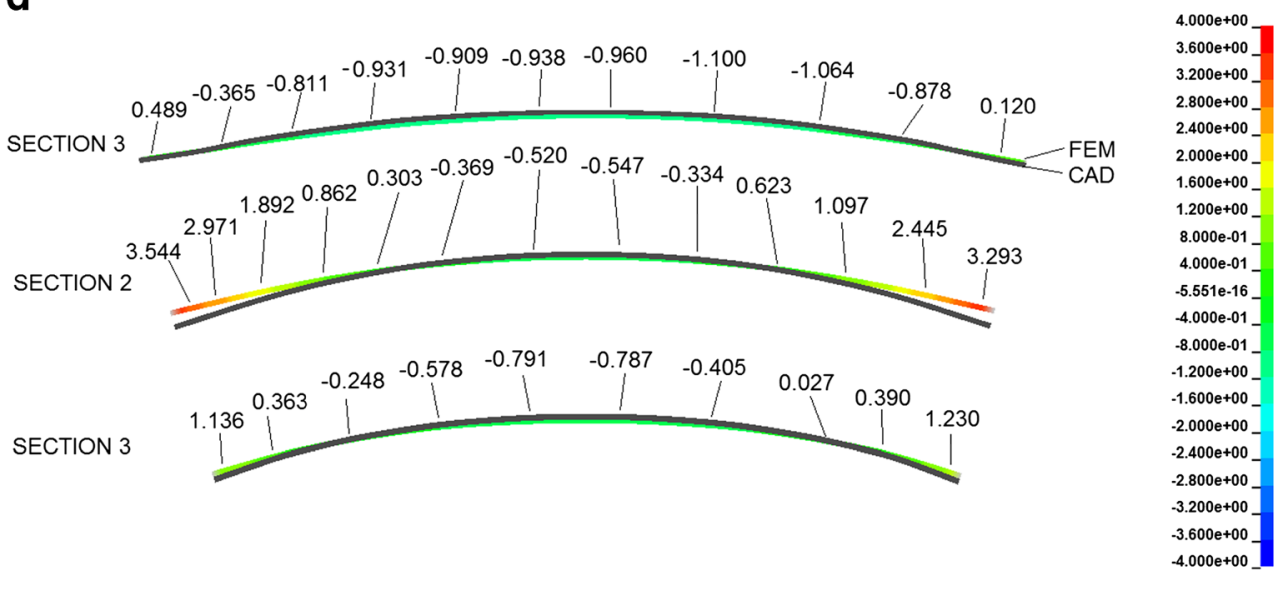

The predicted and measured shape deviations for the different forming cases are presented in Figs. 18, 19, and 20 . The shape deviation can be concluded to be significant for the part that is crash formed $\left(F_{1}\right)$ without a subsequent holding time in the tool, about $5.5 \mathrm{~mm}$ in total (c.f. Fig. 18). The subsequent holding times in the closed state at the end of the hot forming procedure have a major influence on the amount of springback and the resulting shape deviation. Both the short $\left(F_{2}\right)$ and the longer $\left(F_{3}\right)$ holding times result in a substantially decreased amount of springback and shape deviations of about 0.5 and $0.3 \mathrm{~mm}$, respectively. Compare Figs. 19 and 20 with Fig. 18. The resulting geometries from the forming procedures of $F_{2}$ and $F_{3}$ are within the industrial shape tolerance $( \pm 0.35 \mathrm{~mm})$. The chosen tool coating prevent adhesion of the titanium part to the tool punch and die material and prevent oxidation of the tool surfaces. It was found of great importance to use a gentle and symmetric method to remove the part from the tool in order to avoid undesired shape distortions of the hot components upon removal (see example in Fig. 21). 
Fig. 19 a Measured and b predicted shape deviation [mm] of the produced geometry hot formed at approximately $700{ }^{\circ} \mathrm{C}$ with a subsequent holding time of $150 \mathrm{~s}$ in the closed stage of the tool $\left(F_{2}\right)$. c Measured sections and d predicted sections of shape deviation $(\mathrm{mm})$ a
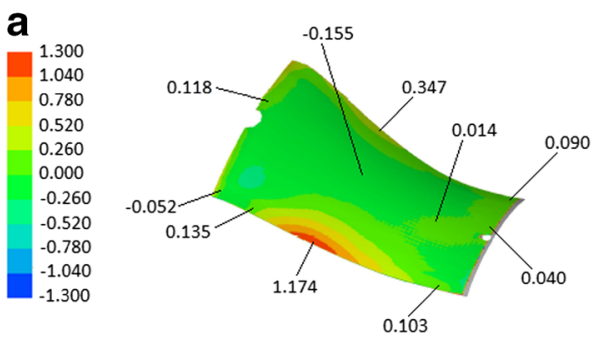

b

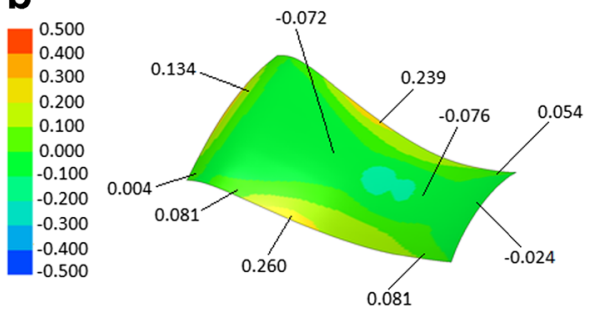

\section{C}
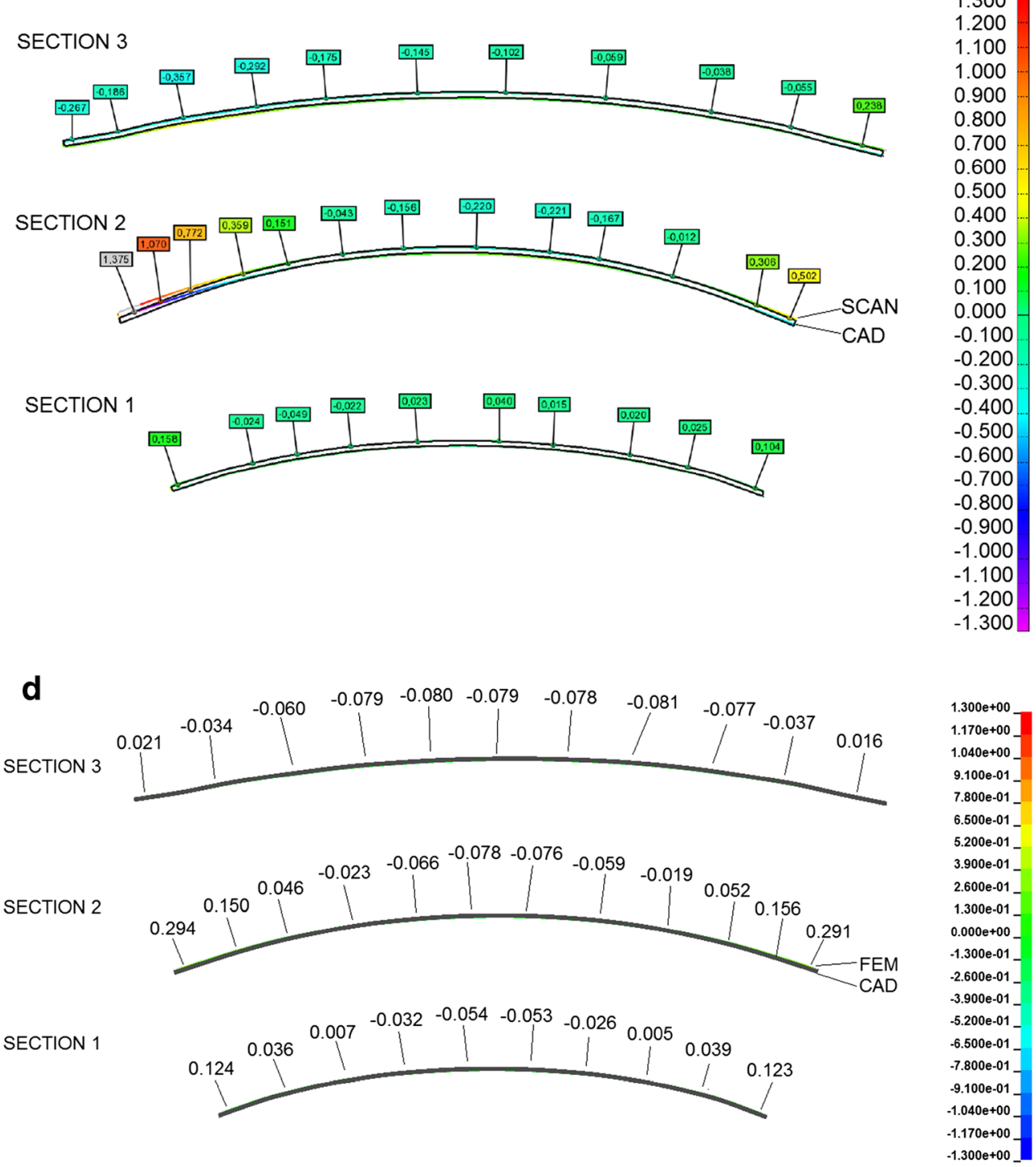

In hot formed titanium aero engine components, it is desirable to maintain the as-received microstructure and mechanical properties. Therefore, it is important to keep the hot forming temperature, as well as the time at elevated temperature, as low as possible. It is also of importance to minimize the formation of an alpha case layer during hot forming. Alpha case starts to form when the temperature exceeds approximately $480^{\circ} \mathrm{C}$, which allows oxygen to diffuse more readily into the bulk material. The alpha case thickness increases with time and temperature and leads to a dramatic increase in material hardness and a subsequently drastic decrease in the ductility [1, 49]. During hot forming, an increasing processing time at elevated temperatures results in an increased alpha case thickness. 
Fig. 20 a Measured and b predicted shape deviation [mm] of the produced geometry hot formed at approximately $700{ }^{\circ} \mathrm{C}$ with a subsequent holding time of $900 \mathrm{~s}$ in the closed stage of the tool $\left(F_{3}\right)$. $\mathbf{c}$ Measured sections and d predicted sections of shape deviation $(\mathrm{mm})$
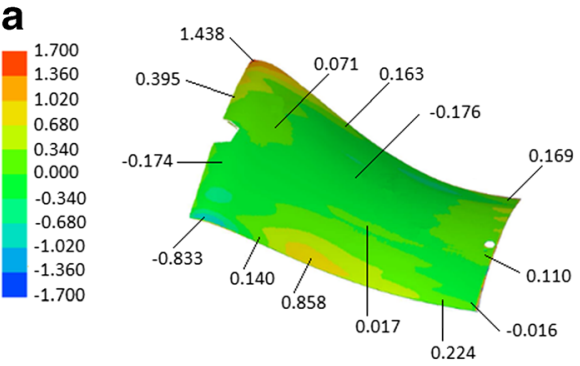

b

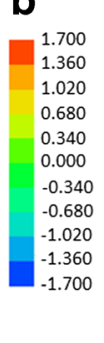

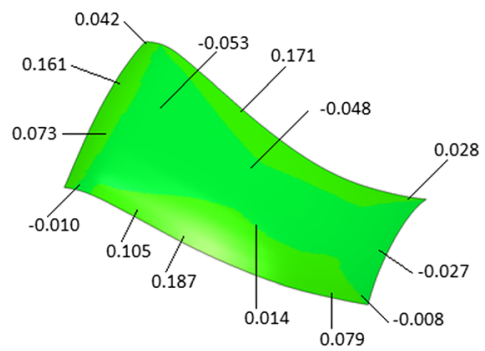

C
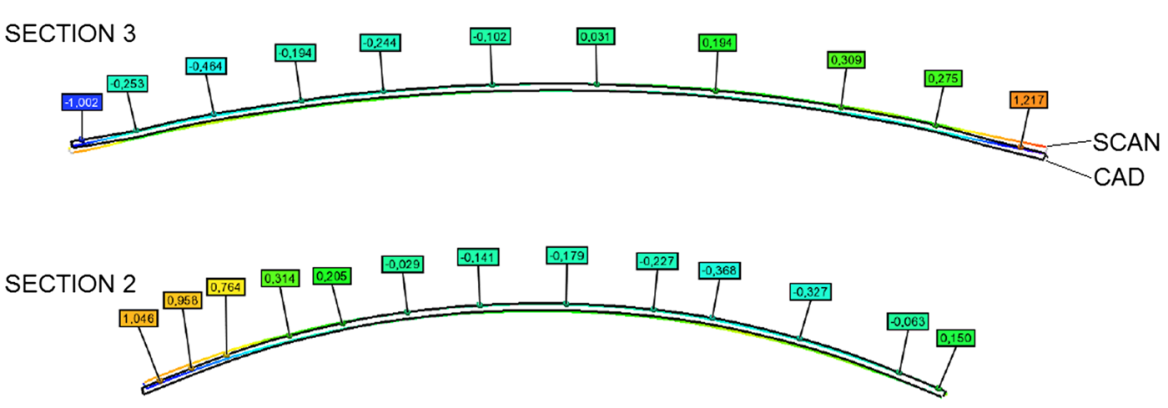

0.500

0.250

0.000

$-0.250$

SECTION 1

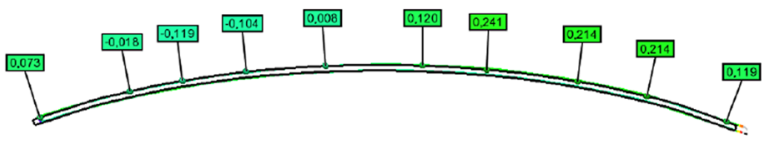

$-0.500$

d

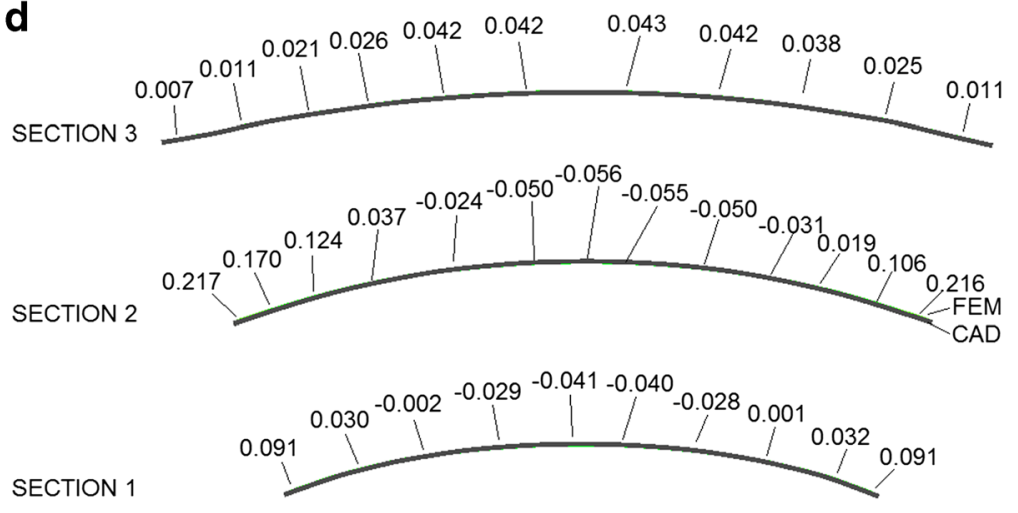

$1.700 \mathrm{e}+00$ $1.530 \mathrm{e}+00$ $1.360 \mathrm{e}+00$ $1.190 \mathrm{e}+00$ $1.020 \mathrm{e}+00$ $8.500 \mathrm{e}-01$ $6.800 \mathrm{e}-01$ $5.100 \mathrm{e}-01$ $3.400 \mathrm{e}-01$ 1.700e-01 2.776e-16 $-1.700 \mathrm{e}-01$ $-3.400 \mathrm{e}-01$ $-5.100 \mathrm{e}-01$ $-6.800 \mathrm{e}-01$ $-8.500 \mathrm{e}-01$ $-1.020 \mathrm{e}+00$ $-1.190 \mathrm{e}+00$ $-1.360 \mathrm{e}+00$ $-1.530 \mathrm{e}+00$ $-1.700 e+00$

The resultant hot formed microstructures and alpha case formations are presented in Fig. 22. It is concluded that the formed part using the process with a short holding time of $150 \mathrm{~s}\left(F_{2}\right)$ does not contain any detectable alpha case using only an optical microscope, whereas the longer holding time of $900 \mathrm{~s}\left(F_{3}\right)$ results in a layer of alpha case (shown by the white layer on the top of the material in Fig. 22b). The asreceived microstructure is preserved for all three of the forming procedures.

\section{Conclusions and discussions}

The present study illustrates the possibility of producing the double-curved geometry within shape tolerance by designing the hot forming process using FE analyses. The use of a model that can account for both anisotropy and time-dependent effects, such as stress relaxation, is crucial to the accuracy of the springback and shape deviation FE predictions during hot Ti$6 \mathrm{Al}-4 \mathrm{~V}$ forming. The major findings are: 
Fig. 21 Measured shape deviations $(\mathrm{mm})$ of the produced geometries hot formed at approximately $700{ }^{\circ} \mathrm{C}$ with a subsequent holding time of $150 \mathrm{~s}$ $\left(F_{2}\right)$. a Part removed from the tool using a pincer and $\mathbf{b}$ part removed from the tool using a gentle and symmetric lifting device. c Measured sections of shape deviation $(\mathrm{mm})$ for the part removed from the tool using a gentle and symmetric lifting device.
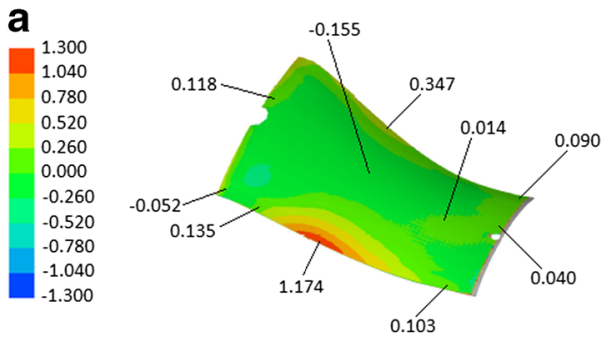

b
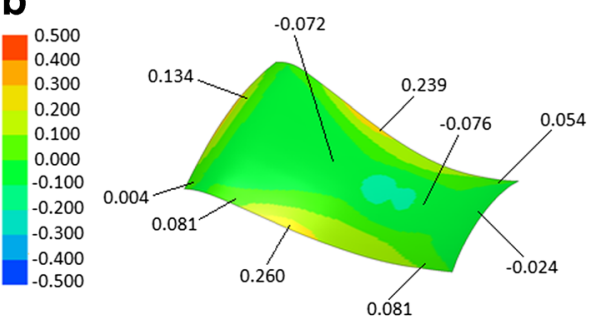

C

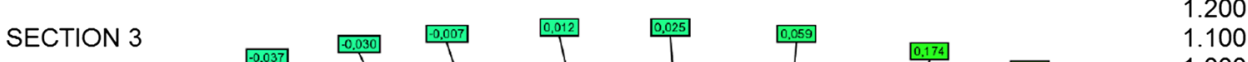

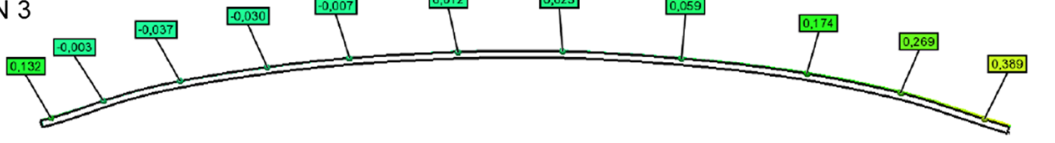

1.000

0.900

0.800

0.700

0.600

SECTION 2

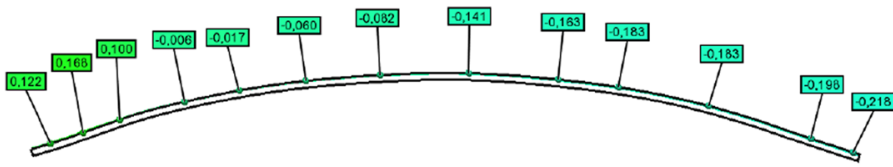

0.400

0.300

0.200

0.100

0.000

$-0.100$

$-0.200$

$-0.300$

SECTION 1

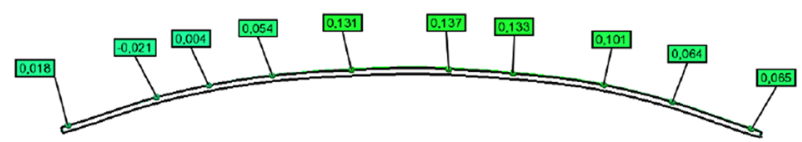

- The material tests confirmed the highly anisotropic temperature and time-dependent properties of Ti-6Al-4V alloy in which the initial yield stress in the 45-direction is comparatively lower than in the two other directions $(00,90)$, for all evaluated temperatures, whereas the Lankford coefficients is substantially higher in the 45-direction compared to the other two directions.

- The initial rate of stress relaxation is high at the very beginning of the stress relaxation tests and decreases with time. This implies that the largest effect of a post forming holding time may be expected at high temperatures and towards the beginning of the procedure. To reduce the residual stresses further, a substantial increase in the holding time may be required.

- The suggested stress relaxation equation was found applicable to describe the relaxation behavior of Ti-6Al-4V.

- A symmetric anisotropic yield criterion such as the Barlat et al. can be applicable to hot forming in Ti-6Al-4V if
Fig. 22 Material micro-structure post forming at a $700{ }^{\circ} \mathrm{C}$ for a short holding time of $150 \mathrm{~s}\left(F_{1}\right)$ and $\mathbf{b}$ a long holding time of $900 \mathrm{~s}$ $\left(F_{2}\right)$. The rolling direction is horizontal in the figures
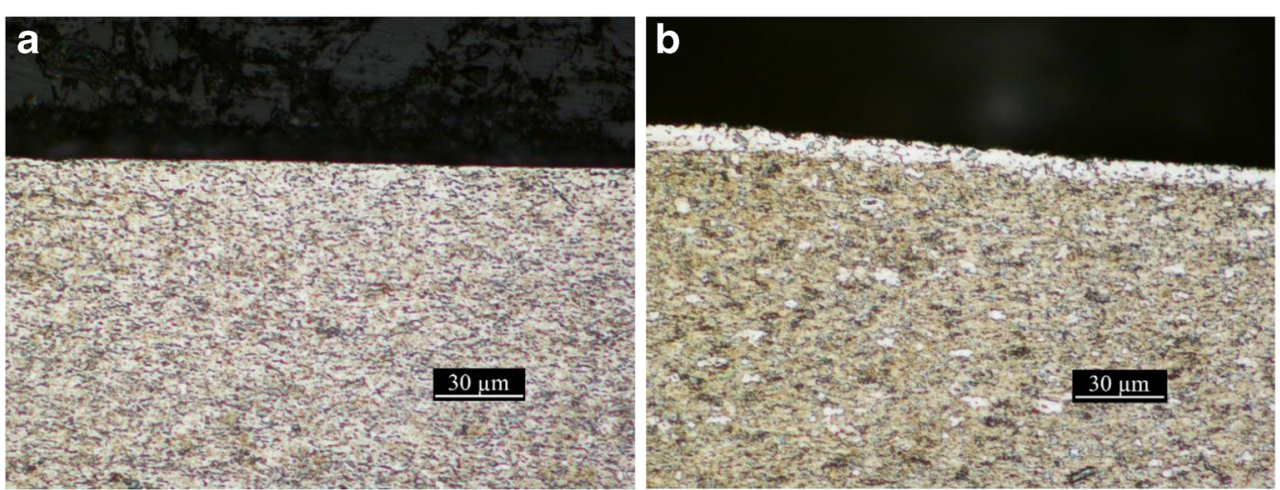
yielding during forming does not occur in the negative plane stress space quadrants, due to tension-compression asymmetry in Ti-6Al-4V. The FE-predicted stress state at the end position of the hot forming procedure in this study reviles that the part is mainly in the elastic regime and that yielding occurs in the positive $\sigma_{11} / \sigma_{22}$ quadrant.

- From the model predictions and hot forming tests, it was concluded that a short holding time of only $150 \mathrm{~s}$ is needed and sufficient to substantially reduce the amount of springback and obtain part geometries within shape tolerance c.f. Figs. 19b, d and 21b, c.

- The developed hot forming procedure has a cycle time seven times shorter than presently adopted in the industry, from approximately $60 \mathrm{~min}$ including blank heating and a 20-min post-forming holding time [50] to only $8.5 \mathrm{~min}$ including blank heating and a post-forming holding time of $2.5 \mathrm{~min}$.

- No alpha case was visually detected using optical microscopy on the part surface when formed using the shorter holding time $\left(F_{2}\right)$, whereas a thin layer of alpha case forms during the process with the longer holding time of $900 \mathrm{~s}$ $\left(F_{3}\right)$. This implies that also time and cost savings can be expected not only in the forming procedure but also in the subsequent etching process used to eliminate alpha case from the hot formed Ti-6Al-4V parts in $\left(F_{2}\right)$.

The model predictions show promising agreement with the measured shape deviations. One reason for the observed deviation depends on the assumption of isothermal conditions during forming and subsequent holding times. Another source of deviation is related to regions where the component was clamped during removal from the hot forming tool, i.e., in the lower left corner and upper long edge part side in Fig. 18a and in the upper left corner and lower longer part edge in Figs. 19a and 20a. A gentle and symmetric method for part removal is necessary to avoid undesirable shape distortions due to removal of the hot components, such as that developed for the part presented in Fig. 21b and c. The areas with large deformation due to the removal of the parts causes difficulties in the best fit evaluation procedure. A better method to evaluate shape distortions for these parts would be to use a global reference system with datum points on the geometry.

By using FE analyses, the optimal hot forming and holding time process parameters can virtually be identified, e.g., forming velocity, temperatures, and holding times. Such a virtual working methodology has potential to speed up the design of new forming procedures for different alloys, it makes virtual compensation of the forming tooling for remaining springback possible provided that accurate thermo-mechanical material model input data are available (Young's modulus. initial yield stress, hardening, Lankford coefficients, and stress relaxation data at different temperatures).
An interesting extension to the present study would be to investigate and include the direction dependence of the stress relaxation behavior and to include the exact temperature distribution of the tool parts with heat transfer to the blank in coupled thermo-mechanical FE analyses. In hot forming procedures where the deformation rate is extremely slow such as in super plastic forming, it may be necessary to implement a model in which the time-dependent relaxation behavior is accounted for also in the forming FE analysis.

Acknowledgements The support from VINNOVA NFFP grants 200901365 and 2014-00919, GKN Aerospace Sweden AB, ITE Fabriks AB, Uddeholms AB, A-Tooling AB, and DYNAmore Nordic AB are greatly appreciated.

Open Access This article is distributed under the terms of the Creative Commons Attribution 4.0 International License (http:// creativecommons.org/licenses/by/4.0/), which permits unrestricted use, distribution, and reproduction in any medium, provided you give appropriate credit to the original author(s) and the source, provide a link to the Creative Commons license, and indicate if changes were made.

\section{References}

1. Gaddam R, Antti M-L, Pederson R (2014) Influence of alpha-case layer on the low cycle fatigue properties of Ti-6Al-2Sn-4Zr-2Mo alloy. Mater Sci Eng A 599:51-56

2. Gaddam R, Sefer B, Pederson R, Antti M-L (2013) Study of alpha case depth in Ti-6Al-2Sn-4Zr-2Mo and Ti-6Al-4V. IOP Conf Ser Mater Sci Eng 48:012002. https://doi.org/10.1088/1757-899X/48/ $1 / 012002$

3. Sefer B, Josep J, Mateo A, Pederson R, Antti M-L (2015) Evaluation of the bulk and alpha-case layer properties in Ti-6Al$4 \mathrm{~V}$ at micro and Nano-metric length scale, 13th World Conference on Titanium 2015, August 16th to 20th, San Diego, California, USA

4. Babu B, Lindgren L-E (2013) Dislocation density based model for plastic deformation and globularization of Ti-6Al-4V. Int J Plast 50: 94-108

5. Lütjering G, Williams JC (2003) Titanium. Springer-Verlag, Berlin Heidelberg

6. Wang G, Zhang KF, Wu DZ, Wang JZ, Yu YD (2009) Superplastic forming of bellows expansion joints made of titanium alloys. $\mathrm{J}$ Mater Process Technol 178:24-28

7. Semiatin SL, Seetharaman V, Weiss I (1998) Hot workability of titanium and titanium aluminide alloys - an overview. Mater Sci Eng A A243:1-24

8. Ding R, Guo ZX, Wilson A (2002) Microstructural evolution of a Ti-6Al-4 V alloy during thermomechanical processing. Mater Sci Eng A 327:233-245

9. Nemat-Nasser S, Guo W-G, Nesterenko VF, Indrakanti SS, Gu Y-B (2001) Dynamic response of conventional and hot isostatically pressed Ti-6Al-4V alloys: experiments and modeling. Mech Mater 33(8):425-439

10. Picu RC, Majorell A (2002) Mechanical behaviour of Ti-6Al-4V at high and moderate temperatures - part II: constitutive modelling. Mater Sci Eng A 326:306-316

11. Deng T, Li D, Li X, Ding P, Zhao K (2016) Material characterization, constitutive modeling and validation in hot stretch bending of Ti-6Al-4V profile. J Mech Manuf 230(3):505-516 
12. Khan A, Kazmi R, Farrokh B (2007) Multiaxial and nonproportional loading responses, anisotropy and modelling of Ti$6 \mathrm{Al}-4 \mathrm{~V}$ titanium alloy over a wide ranges of strain rates and temperatures. Int J Plast 23:931-950

13. Huh H, Ahn K, Lim JH, Kim HW, Park LJ (2014) Evaluation of dynamic hardening models for BCC, FCC, and HCP metals at a wide range of strain rates. J Mater Process Technol 214:1326-1340

14. Kopeca M, Wanga K, Politisa DJ, Wangb Y, Wanga L, Lin J (2018) Formability and microstructure evolution mechanisms of Ti6Al4V alloy during a novel hot stamping process. Mater Sci Eng A 719: $72-81$

15. Ambrogio G, Palumbo G, Sgambitterra E, Guglielmi P, Piccininni A, De Napoli L, Villa T, Fragomeni G (2018) Experimental investigation of the mechanical performances of titanium cranial prostheses manufactured by super plastic forming and single-point incremental forming. Int J Adv Manuf Technol 98:1489-1503

16. Ma J, Li H, Wang D, Fu MW, Tao ZJ (2018) Tribological behaviors in titanium sheet and tube forming at elevated temperatures: evaluation and modeling. Int J Adv Manuf Technol 97:657-674

17. Hamedon Z, Mori K, Maeno T (2013) Hot stamping of titanium alloy sheet using resistance heating. NMSTU 5:12-15

18. Maeno T, Yamashita Y, Mori K-I (2016) Hot stamping of titanium alloy sheets into U shape with concave bottom and joggle using resistance heating. Key Eng Mater 716:915-922

19. Ozturk F, Ece RE, Polat N, Koksal A, Evis Z, Polat (2013) A Mechanical and microstructural evaluations of hot formed titanium sheets by electrical resistance heating process. Mater Sci Eng A 578:207-214

20. Kotkunde N, Deole AD, Gupta A, Singh SK (2014) Experimental and numerical investigation of anisotropic yield criteria for warm deep drawing of Ti-6Al-4V alloy. J Mater Des 63:336-344

21. Odenberger E-L, Oldenburg M, Thilderkvist P, Stoehr T, Lechler J, Merklein M (2011) Tool development based on modelling and simulation of hot sheet metal forming of Ti-6Al-4V titanium alloy. J Mater Process Technol 211(8):1324-1335

22. Odenberger E-L, Schill M, Oldenburg M (2013) Thermomechanical sheet metal forming of aero engine components in Ti6Al-4V: Part 2: constitutive modelling and validation. Int J Mater Form 6(3):403-416

23. Odenberger E-L, Thilderkvist P, Oldenburg M (2014) Springback and stress relaxation in thermo-mechanical forming of thin Ti-6Al4V sheets, Int. Symp. Plasticity 2014, Grand Lucayan Resort, Freeport, Bahamas, January 3-8

24. Zong Y, Liu P, Guo B, Shan D (2015) Springback evaluation in hot v-bending of Ti-6Al-4V alloy sheets. Int J Adv Manuf Technol 76: $577-585$

25. Hill R (1950) The mathematical theory of plasticity. Clarendon Press, Oxford

26. Barlat F, Lian J (1989) Plasticity behaviour and strechability of sheet metals Part I: a yield function for orthotropic sheets under plane stress condition. Int J Plast 5:51-66

27. Jansson M, Nilsson L, Simonsson K (2005) On constitutive modelling of aluminium alloys for tube hydroforming applications. Int $\mathrm{J}$ Plast 21:1041-1058

28. Lademo OG, Hopperstad OS, Langset M (1999) An evaluation of yield criteria and flow rules for aluminium alloys. Int J Plast 15: 191-208

29. Hosford W (1979) On the yield loci of anisotropic cubic metals. 7th North American Metalworking Conf. SME, Dearborn, MI. 191-197

30. Barlat F, Aretz JCH, Yoon W, Karabin K, Breem ME, Dick RE (2005) Linear transformation-based anisotropic yield functions. Int J Plast 21:1009-1039
31. Barlat F, Brem JC, Yoon J, Chung WK, Dick RE, Lege DJ, Pourboghrat F, Choi S-H, Shu E (2003) Plane stress yield function for aluminium alloy sheet - part1: theory. Int J Plast 19:1297-1319

32. Cazacu O, Barlat F (2006) Orthotropic yield criterion for hexagonal closed packed metals. Int J Plast 22:1171-1194

33. Abedrabbo N, Pourboghrat F, Carsley J (2006) Forming of aluminum alloys at elevated temperatures - part 1: material characterization. Int J Plast 22:314-341

34. Abedrabbo N, Pourboghrat F, Carsley J (2007) Forming of AA5182-O and AA5754-O at elevated temperatures using coupled thermo-mechanical finite element models. Int J Plast 23:841-875

35. Ghavam K, Bagheriasl R, Worswick MJ (2014) Analysis of nonisothermal deep drawing of aluminum alloy sheet with induced anisotropy and rate sensitivity at elevated temperatures, J. Manuf Sci Eng 136:0110061-0110016

36. Khan A, Baig M (2011) Anisotropic responses, constitutive modeling and the effects of strain-rate and temperature on the formability of an aluminum alloy. Int J Plast 27:522-538

37. Ghaffari Tari D, Worswick MJ (2015) Elevated temperature constitutive behavior and simulation of warmforming of AZ31BD. J Mater Process Technol 221:40-55

38. Ghaffari Tari D, Worswick MJ, Ali U, Gharghouri M (2014) Mechanical response of AZ31B magnesium alloy: experimental characterization and constitutive modeling considering proportional loading. Int J Plast 55:247-267

39. Zhou Z, Bhamare S, Ramakrishnan G, Mannava S, Langer K, Wen Y, Qian D, Vasudevan V (2012) Thermal relaxation of residual stress in laser shock peened Ti-6Al-4 V alloy. Surf Coat Technol 206:4619-4627

40. Boyer R, Welsch G, Collings EW (1994) Materials properties handbook: titanium alloys. ASM International, pp 483-636

41. IMCE 2003 (2018) http://www.imce.net/products

42. Odenberger E-L, Hertzman J, Thilderkvist P, Merklein M, Kuppert A, Stöhr B, Lechler J, Oldenburg M (2013) Thermo-mechanical sheet metal forming of aero engine components in Ti-6Al-4V: Part 1: Material characterization, Odenberger. Int J Mater Form 6(3):391-402

43. Grant BMB, Stone HJ, Withers PJ, Preuss M (2009) Hightemperature strain field measurement using digital image correlation. J Strain Anal 44:263-271

44. ARAMIS v6 (2018) http://www.gom.com.

45. Sigvant M, Mattiasson K, Vegter H, Thilderkvist P (2009) A viscous pressure bulge test for the determination of a plastic hardening curve and equibiaxial material data. Int J Mater Form 2(4):235-242

46. Hallquist JO (2006) LS-DYNA theory manual. Livermore Software Technology Corporation, Livermore

47. Rowan TH (1990) Functional stability analysis of numerical algorithms, Doctoral thesis, The University of Texas at Austin, USA

48. DYNAFORM (2018) https://www.eta.com/33-dynaform

49. Gaddam R, Sefer B, Pederson R, Antti M-L (2015) Oxidation and alpha-case formation in Ti-6Al-2Sn-4Zr-2Mo alloy. Mater Charact 99:166-174

50. Information given by GKN Aerospace Sweden AB and existing sub-supplier for the geometry studied in this work

Publisher's note Springer Nature remains neutral with regard to jurisdictional claims in published maps and institutional affiliations. 